Thorax (1947), 2, 121.

\title{
COARCTATION OF THE AORTA
}

\author{
BY \\ C. CRAFOORD, B. EJRUP, AND H. GLADNIKOFF* \\ Stockholm
}

[For Plates see pages 139-147]

INTRODUCTION

The relatively bad prognosis in cases of aortic coarctation seemed to be sufficient justification for making an attempt at surgical treatment in these patients. One of us (Crafoord), during work with patent ductus arteriosus and as the result of both experimental and clinical studies of the circulatory conditions existing when the aorta is shut off at different levels, gradually came to the conclusion that the surgical risk would not be too great.

In experimental studies on dogs, Crafoord (1939) demonstrated that the flow of blood to all the organs could remain suspended for as long as twenty to twenty-five minutes without any subsequent sign of organic damage, provided an adequate flow to the brain was secured. This circulation to the brain was maintained by creating anastomoses between the carotid and jugular vessels on one side in the animal under operation with the corresponding vessels in a dog of the same size lying beside it. On the strength of this observation Crafoord took the risk, in certain patients with a patent ductus arteriosus, of placing clamp forceps on the aorta above and below the point of entry of the duct into this artery and of keeping them attached during the time necessary to divide the duct and suture the aorta. In one of the patients this part of the operation took no less than 27 minutes to perform. In spite of this long period, during which the aorta was shut off just below the point where the subclavian artery arises, no noticeable disturbances were subsequently observed in the patient's internal organs.

As far as we have been able to ascertain from the literature, the only other investigator besides Crafoord who has considered the possibility of relieving coarctation of the aortic isthmus by a surgical intervention is Blalock (Blalock and Park, 1944 ; Blalock and Taussig, 1945). The latter, however, approached the problem in a more conjectural manner and from a different standpoint, having considered some form of anastomosing operation or plastic reconstruction

\footnotetext{
* From the Surgical Clinic I, Medical Clinic II, and Radiological Department of the: Sabbatsberg Hospital, Stockholm.
} 
to be the only way of improving the circulation peripheral to the stricture. He also stated that no intervention to correct coarctation had yet been performed on man.

In the light of his experimental results and of the clinical experiences gained from operations for patent ductus arteriosus, Crafoord considered that in patients with congenital isthmic stenosis who already possessed a well-developed and satisfactorily functioning collateral arterial system he could venture to keep the aorta closed at a point immediately peripheral to the left subclavian artery for a period considerably longer than 27 minutes without causing danger to the patient through cutting off the blood flow to organs in the part of the body supplied with arterial blood from arteries peripheral to the aortic stenosis.

The possibility of surgical resection was discussed with Professor Nylin during the summer of 1944, and by a strange coincidence two patients with coarctation of the aorta were sent to our hospital at about this time for an opinion In both cases, after investigation in the Department of Cardiology by Nylin, we decided to operate.

\section{THE OPERATION}

The operation was planned as a trial thoracotomy in order to ascertain whether the aortic wall was in a condition to permit circular suture of the vessel after resection of the stricture. If the aortic wall showed signs of morbidity, or if, after mobilization, it seemed unlikely that the aorta could be made sufficiently mobile to allow coaptation of the resected edges without tension after the removal of the stricture, we intended to abandon the operation and make no attempt to relieve the stenosis.

Crafoord operated on the first patient on October 19,1944, and upon 6 other cases between this date and January 10, 1946 (but see addendum).

The operations were carried out under general cyclopropane and nitrous oxide anaesthesia, with controlled respiration during the whole operation produced mechanically by a special anaesthetic machine described by Crafoord (1939 and 1940). This machine has been used in Crafoord's department for all major intrathoracic operations, which now number about 1,000. Its construction is such that the breathing rate, the amount of gas given at each inspiration, and the length of the inspiratory and expiratory phases can all be regulated mechanically. The inspiratory phase is continued until the gas insufflated into the lungs reaches a predetermined and controllable maximum pressure of about $200 \mathrm{~mm}$. of water, and there is then an automatic switch-over to free unimpeded expiration. Thus, no pressure injurious to the lungs can be produced in the system. The task of the anaesthetist is, therefore, to check that the apparatus is functioning correctly and to keep a watch on the depth of anaesthesia and the patient's circulation. Controlled respiration during an intrathoracic operation makes the type of breathing and gas exchange closely resemble natural breathing under normal conditions. It is also of great value to the surgeon when he desires complete immobility in the operation field, because all respiratory muscles are motionless under these conditions. This is of particular importance for all deep, technically difficult work, and especially for the minute work involved in resection of the aorta for coarctation. 
In the first case the chest was opened through the lateral thoracotomy incision which is normally used in Crafoord's clinic (1938). The pleural cavity was opened by removing the fifth rib from the transverse process to the cartilage. The aorta was then exposed. The mediastinal parietal pleura was divided longitudinally from the origin of the subclavian artery above down to a point about $5 \mathrm{~cm}$. below the stricture. Within the whole of this area the aorta was explored and its entire circumference freed. This procedure presented no great difficulties except with regard to the area of greatest constriction. This segment was short, not more than 4 to $5 \mathrm{~mm}$. in length. The difficulty experienced in exploring the narrowest part was due to the fact that it was embedded in hard fibrous tissue. This fibrous tissue passed over into a cord of connective tissue not quite as thick as a slate pencil, which could be readily isolated. It began on the medial posterior aspect, where the stricture was most pronounced, and after a little more than $1 \mathrm{~cm}$. it passed into the wall of the pulmonary artery about at the point where this divides into the left and right main branches. The recurrent laryngeal nerve, after leaving the vagus, hooked around this fibrous structure before passing upwards towards the neck. The appearances of the coarctations are shown in the schematic drawings of the three first cases (Plate Ia). The following four cases differed in no material respect. The intercostal vessels arising from the aorta on either side of the stricture were also freed. These vessels were dilated and slightly tortuous, both above and below the constricted segment. The aorta was then clamped with a special pair of artery clamps just below the point of the origin of the subclavian artery, and a similar pair of clamps was placed on the distal portion of the aorta as far down as possible below the first pair of intercostal arteries. Small artery clamps were then placed on all the branches arising from the aorta between the two forceps on the main trunk. Resection of the constricted segment of the aorta was then carried out. The intercostal arteries, with one exception, were not divided. The line of section of the aorta was planned so that the resulting lumina of the cut ends of the aorta were approximately equal. Sometimes the line of resection will be transverse on both segments, and sometimes transverse on one and oblique on the other, as was the case in the two first resections. The segments of the aorta removed from two patients are shown in Plate $I b$.

When doing the aortic anastomosis three interrupted sutures were first placed at equal distances from each other, and then a running silk suture was sewn between the interrupted ones, carefully excluding the intima; each stitch was drawn up separately, as devised by Carrel, to secure adequate tautness. In the later cases, only two stay sutures were used. In none of the patients was there any difficulty in coapting the two lumina of the aorta, and when the forceps were removed the suture lines were sound with no leak and without undue tension, except in case 4, where a further row of interrupted sutures was necessary to stop a leak. The lumen at the site of anastomosis in all cases was about 75 per cent of the normal. The mediastinal pleura was then sewn with a tight con- 
tinuous suture and the chest closed without drainage, any post-operative effusion being dealt with by aspiration.

In 6 patients the wound healed by primary intention; the seventh died suddenly, on the evening of the day of operation, from massive haemorrhage due to cutting through or slipping of a ligature on an intercostal artery which had to be tied as it was injured during the dissection. At necropsy, the aortic anastomosis was intact.

Four of the surviving 6 patients developed minor post-operative complications. At the end of the second week the first developed an acute tonsillitis which was prevalent in the hospital at the time, but recovered quickly. The second patient, who had also been recently operated on and who was in the same room as the first patient when he had his attack of tonsillitis, developed a small opacity at the base of the lung with a temperature of $100^{\circ} \mathrm{F}$. to $101^{\circ} \mathrm{F}$. This settled in a few days with sulphonamide treatment. The third patient was ill-advisedly given heparin about 36 hours after operation, with the result that she developed a considerable haematoma in her chest wound; post-operative aspiration did not reveal any important intrapleural haemorrhage. With this case in mind, we would like to stress that in our opision there is no place for heparin in cases of clean arterial suture. The fourth p'tient was mildly febrile during the first ten days, after which the temperature rose to $101^{\circ} \mathrm{F}$. He then developed a colicky pain in his left loin which lasted two days. Microscopically, the urine showed a few red blood cells. The temperature settled in the course of a few days, and it is probable that he had a small renal embolism.

\section{Addendum}

Up to the end of 1946, 15 coarctations in all had been resected. One death occurred in the last 8 ; this was due to a false aneurysm caused by insufficiency of the aortic suture line. This patient died about one month after the aortic resection.

Two more patients have been explored; in both it was impossible to perform a resection, in one because of the hypoplastic condition of the aortic wall, and in the other because of extensive arteriosclerosis. The former of these died from post-operative pneumonia.

\section{Historical NOTES}

Coarctation of the aorta has been known since Morgagni (1760) first mentioned the abnormality and since the anatomist Paris (1791) made a thorough report on a case. The first description of a large number of casęs was by Wadstein (1897), a Swedish investigator, who collected 103 from the literature. Maud Abbott (1931) in her classical work found 142 examples of this abnormality in 1,000 patients with congenital cardiovascular defects. 
There are two types of coarctation of the aorta: the infantile type, which occurs mainly in children up to the age of one year; and the adult type. It is with the latter type only that we are concerned here.

The incidence of this congenital deformity has been estimated by Blackford, on the basis of a series of 68,300 routine autopsies, to be about 1 in 1,500 patients, and by Evans (1933) at the London Hospital to be 1 in 750 when the infantile type was included, but only 1 in 1,500 when this type was excluded. Levine (1940), in Philadelphia, estimated that 0.1 per cent of the entire population suffers from this anomaly. Andreesen (1929) found 4 cases of the adult type among 17,000 autopsies from the hospitals of Hamburg. At Lund, although 500 autopsies were performed yearly, Ask-Upmark (1942) reported that only 4 cases were diagnosed between 1897 and 1942.

Perlman (1944), when examining an unselected group of men between 18 and 35 years of age for army service, found an incidence of only about 1 in 10,000 . It is difficult to explain these discrepancies. Possibly, the pathologists have included the non-clinical group of cases, in which the narrowing of the aorta is so slight that it produces no clinical symptoms, while some of the coarctation cases have been misdiagnosed in the series reported by clinicians. In our own small experience of 7 cases which have been resected, most of the patients had been examined by several physicians before the diagnosis was made.

Coarctation of the aorta is much commoner among men than among women. Maud Abbott gives the proportion as 3 to 1 . Among the 7 patients on whom we have operated at the Sabbatsberg Hospital only one was a woman.

\section{Pathology}

From the point of view of pathological anatomy there is no essential difference between the infantile and the adult form of coarctation. As far as the aortic lesions are concerned it is more a difference in degree than in type. In the infantile form the more or less pronounced constriction embraces a larger segment of the aorta. It is owing to this, as well as to the fact that the infantile type is very often associated with other serious anatomical abnormalities of heart and blood vessels, that children with these abnormalities seldom live longer than the first hours after birth.

In the adult form the aortic stricture is usually confined to the area where the ductus arteriosus is situated in the foetus. Other disturbances of development are not so common in adults. There are three principal developmental disturbances which may be associated with the adult form of coarctation of the aortic isthmus. The commonest is the bifid aortic cusp which, in Abbott's statistics, has an incidence of 25 per cent. Next in order comes hypoplasia of the aortic wall, which is of considerable surgical importance; Abbott found this in 10 per cent of her series. Thirdly, there are isolated cases in which the points of origin 
of the great vessels leaving the aortic arch are abnormally situated, and also cases of patent ductus arteriosus.

A pathological change which seems to be caused by the congenital deformity is the early appearance of arteriosclerosis in the arteries proximal to the narrowed segment. There are no autopsy reports available regarding the incidence of arteriosclerosis in various age groups. This information would be interesting from the surgical point of view. The oldest patient upon whom we have operated was aged 27, and several have been around the age of 20 , but nevertheless we have not observed arteriosclerotic changes in any of them (but see addendum).

The average length of life in patients with coarctation seems to be low. Ask-Upmark (1942) stated that, judging by the information in the literature, about 25 per cent of all cases die before they reach the age of 20 years, that onehalf of all cases do not survive beyond the age of $\mathbf{4 0}$ years, and that 90 per cent have died before the age of 50 years. Thus, only 10 per cent of all cases live to 50 years or over. In Maud Abbott's review the average age was 32 years. These figures, which are based on autopsy material, perhaps paint an unduly gloomy picture of the situation, but we think they come fairly near the truth. The greater interest shown during the past few years in an exact diagnosis of this complaint has not, in fact-at least not in Sweden-increased the number of newly discovered cases with a clinically benign course in an older age-group. It is also a rare occurrence for coarctation of the aorta to.be accidentally discovered in post-mortem examination of old persons.

The commonest causes of death in these patients, who die relatively young, are to be traced to secondary lesions in the heart and blood vessels. Maud Abbott gives the causes of death, in order of frequency, as congestive heart failure, sudden death due to rupture of the aorta or the heârt, cerebral haemorrhage, and bacterial endocarditis.

\section{Clinical Findings}

Coarctation seems always to be accompanied by increased blood pressure above the level of the coarctation, and decreased pressure below. It is not known how early in infancy these changes in the blood pressure are present. In a 3-yearold child reported by Bodlander (1946) the blood pressure was $130 / 60 \mathrm{~mm}$. Hg in the right arm and $120 / 60 \mathrm{~mm}$. $\mathrm{Hg}$ in the left arm, and erosions of the ribs were seen in the radiograph. That is hypertension at this age. The blood pressure in the legs was not recorded. We are of the opinion that a higher blood pressure in the legs than in the arms practically excludes coarctation. There is only one proven case in the literature with higher pressure in the legs than in the arms, and in this there was only a minimal constriction of the isthmus without any practical importance. (Stewart and Bailey, Jr. (1941), case 11, and Stewart, Haskell, and Evans (1944), case 1, must be the same case.) In our material the blood pressure has been high in the arteries of the upper limbs 
and low in the lower extremities in all patients. In the two youngest, both children of 11 years of age, we found systolic blood pressures ranging in one between 150 and 190, and in the other between 140 and $150 \mathrm{~mm} . \mathrm{Hg}$. A few cases with normal blood pressure (King, 1937) have been mentioned in the literature.

If the presence of hypertension is established in a young person, the possibility of coarctation of the aorta should always be borne in mind, and this condition must be excluded before the diagnosis of juvenile essential hypertension is made.

The subjective symptoms resulting from the hypertension in the upper part of the body vary. Sooner or later the symptoms usually mentioned by hypertensive patients appear, namely, general weakness, palpitation, vertigo, throbbing headache and a feeling of heaviness in the head, and visual troubles. These are often the symptoms which cause the patients to seek medical advice. Table I summarizes the symptoms in our first 7 cases submitted to operation.

TABLE I

SUBJECTIVE SYMPTOMS IN SEVEN SUCCESSIVE CASES OF COARCTATION OF THE AORTA IN THE ORDER OF THEIR APPEARANCE

\begin{tabular}{|c|c|c|c|c|c|c|c|c|c|}
\hline Case No.: & 1 & 2 & 3 & 4 & 5 & & 6 & 7 & Numbers of \\
\hline Age (years): & 11 & 27 & 20 & 18 & 20 & & 11 & 24 & $\begin{array}{c}\text { of each } \\
\text { symptom }\end{array}$ \\
\hline 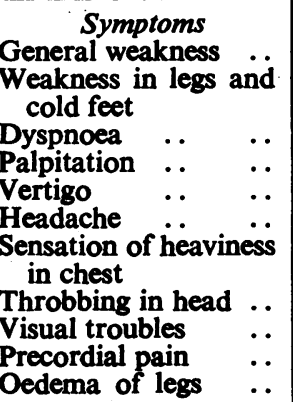 & $\begin{array}{ll}7 & 4 \\
7 & 4\end{array}$ & $\begin{array}{ll}26 & 1 . \\
26 & 1\end{array}$ & 182 & $\begin{array}{ll}10 & 8 \\
10 & 8 \\
& \\
10 & 8\end{array}$ & $\begin{array}{l}18 \\
10 \\
18 \\
18\end{array}$ & $\begin{array}{l}2 \\
10 \\
2 \\
2\end{array}$ & $\begin{array}{ll}7 & 4 \\
7 & 4 \\
7 & 4\end{array}$ & $\begin{array}{l}12 \\
12 \\
23\end{array}$ & $\begin{array}{l}6 \\
4 \\
3 \\
3 \\
3 \\
2 \\
2\end{array}$ \\
\hline
\end{tabular}

The first number in each column is the age in years at which the symptom appeared and the second the number of years the patient had sufiered from it.

The low blood pressure in the lower half of the body, which never occurs in hypertension from other causes, sometimes produces symptoms suggestive of intermittent claudication, often very vague but sometimes quite pronounced, but may cause no subjective symptoms. Four of our patients showed symptoms referable to the legs, but all 7 gave pathological oscillographic readings from the legs after exercise. The oscillographic studies are discussed below. 
Coarctation of the aorta sooner or later gives rise to cardiac cnanges. At first, hypertrophy of the left ventricle develops. Hypertrophy of the left side of the heart is often evident even on percussion. In the majority of cases the hypertrophy is not capable of compensating for the increased effort demanded of the heart, and congestive heart failure then occurs. In all our 7 cases there were clear signs of hypertrophy of the left ventricle at the operation. The left border of the heart was curyed in the manner usually seen in hypertrophy. This is of special interest because the heart volume deduced from radiographic examination by the method of Liljestrand and others (1939) was within normal limits before operation except in case 2 , but after operative relief of the stenosis re-examination showed decrease in heart volume (Plate II).

A common complication is infective endocarditis. We have seen one case in which recovery occurred after combined treatment with a sulphonamide and penicillin.

It is on account of one or more of these three groups of symptoms-hypertension, claudication, and heart symptoms-that the majority of patients consult the physician. At the first inspection and palpation the diagnosis may be suggested by the presence of collateral vessels and by absence of the pulse in leg arteries in which it is normally palpable. The most suitable places to search for pulsating collateral arteries are in the two axillae, the inter-scapular region, the supraspinous fossae, and close to the lower borders of the ribs. As a rule there is no pulse at all in the lower extremities except in the femoral artery near the inguinal ligament, where a weak pulse can sometimes be palpated. In the neck and supraclavicular fossae the pulsations from the great arteries are felt to be much more powerful than normal. The pulsations of collateral arteries can often be seen under the skin of the epigastrium, in the axillae, and the interscapular region.

Over the pulsating collaterals there is usually a late systolic murmur. Special phonocardiographic studies have led to the opinion that the rough or harsh systolic murmur over the base of the heart, which can also be heard at the back -especially in the interscapular region and loudest to the left-comes from the collaterals and not from the stenosis of the aortic isthmus. This systolic murmur disappears after operation (Plate III) and in one case in which stenosis was complete the systolic murmur was present before operation and vanished afterwards, indicating that the murmur was not due to the stenosis itself. In some cases of coarctation there is also a diastolic murmur heard at the base of the heart. This is usually caused by a bicuspid aortic valve with an endocardial lesion or probably a relative incompetence. One of our patients (case 7) had a bicuspid aortic valve, but no diastolic murmur was heard.

Laboratory tests of kidney function in our patients have always been normal. The liver function, on the other hand, has not always been absolutely normal. 
COARCTATION OF THE AORTA

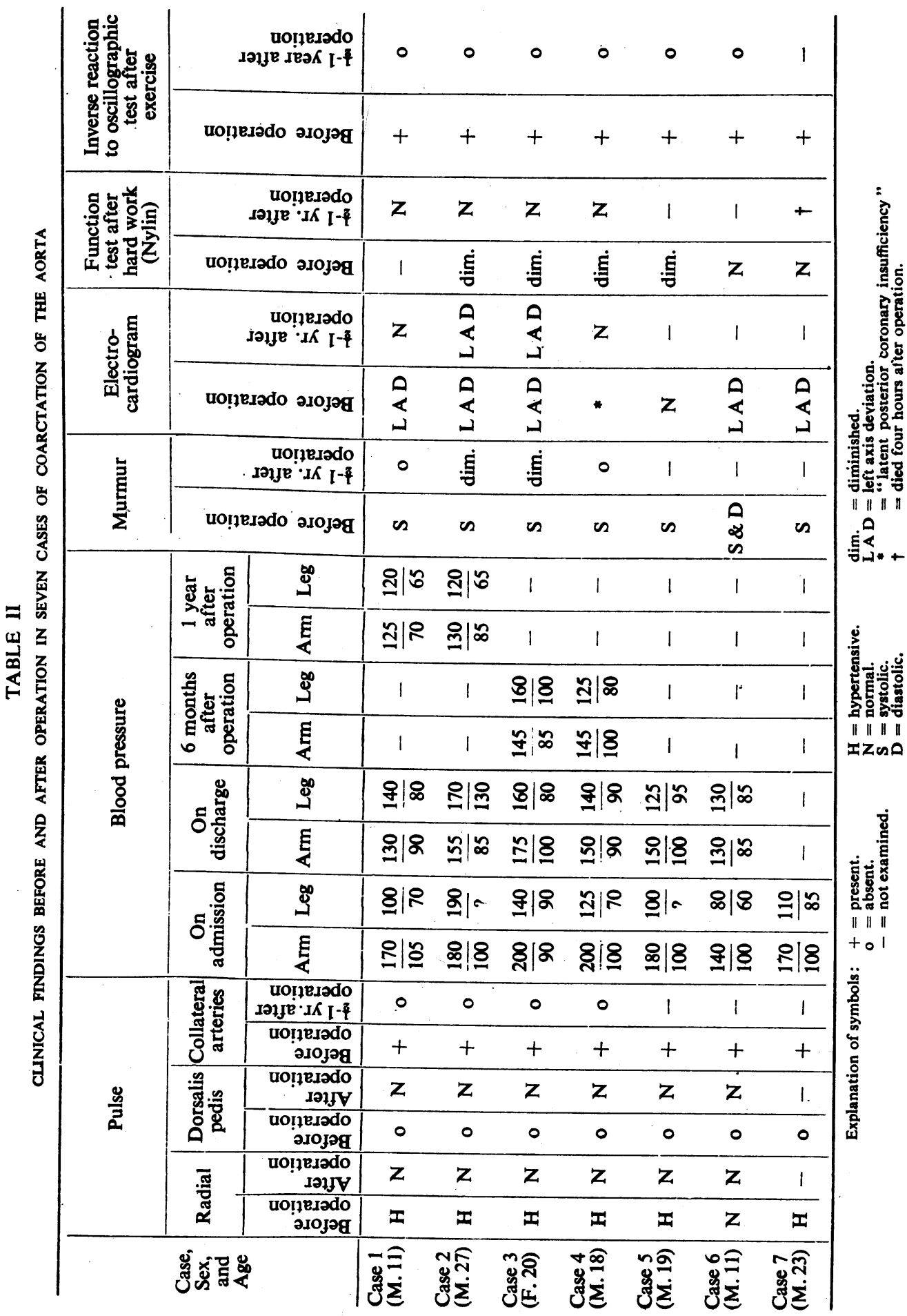


In a few patients the bilirubin values were too high, and in one there was a noticeable reduction in the clotting property of blood.

Clinical data about our first 7 cases submitted to operation are summarized in Tables I and II. Table I presents the symptoms before operation and Table II the clinical findings before and after operation. There were 6 men and 1 woman, ages ranging between 11 and 27 years. Only one was physically under-developed. All complained of fatigue and more or less severe symptoms of claudication. Four out of the 7 (Nos. 2, 3, 5, and 7) had symptoms referable to hypertension. All except the young boys showed cardiac insufficiency, either symptomatically or on cardiological examination or both.

Operation caused great changes in the pulse quality in the upper and lower limbs and in the collaterals. The hypertensive pulse in the arms became normal ; the pulse in the legs, impalpable before operation, became normal afterwards; and the pulse in the collaterals, palpable before operation, became impalpable in patients observed for a longer period of time. There are two exceptions: in case 6 the pulse in the arms was normal before operation, and in case 2 there were no palpable collaterals. Hypertension in the upper limbs and hypotension in the lower limbs were present in all cases before operation, and returned to normal after operation. All patients except case 5 showed some electrocardiographic changes ; 5 showed a left axis deviation and 1 a latent posterior coronary insufficiency (case 4). The first 4 cases, half to one year after operation, showed normal electrocardiograms (ECG) except case 2 in which there is still some left axis deviation. We have found that there are two types of ECG in coarctation ; one with normal QRS-time but very high $R$-waves in leads 2 and 3 and in the chest leads, and the other with left axis deviation and a QRS-complex tending to bundle branch block (Plate IVa).

Professor Nylin's heart function test (Nylin, 1938) was performed before and after operation. Before operation there was a definite insufficiency in 4 cases. Four cases only have been examined after operation, and all showed normal values.

\section{SPECIAL INVESTIGATIONS}

The results of two important investigations have purposely been excluded from Table II ; the oscillographic and the radiographic investigations have been the objects of much work and study at our hospital and we wish to deal with them separately.

\section{Oscillographic and blood pressure studies before and after operation}

The oscillographic examination is carried out with a new apparatus devised by Ejrup (1944) in Professor Nylin's clinic. The recordings can be calibrated and are thus directly comparable at different examinations. The auscultatory method is adequate in studying blood-pressure changes in the upper extremities, 
but in the lower extremities it is often difficult to hear the sounds when auscultating in the popliteal fossa. The oscillogram gives a clear and visible record of the blood pressure and pulsations even in the lower extremities, and is of great interest in coarctation cases because, as shown by Ejrup (1945 and 1946), there is a special reaction to exercise. If in a normal case an oscillogram is taken on the upper or the lower limbs after exercise, the blood pressure and pulsations are greater than in the oscillogram taken during rest (Plate IV $b-\mathrm{A})$. In organic obstruction of the arteries an "inverse reaction" with a diminished blood pressure and a decrease of pulsations appears after exercise (Plate IV $b-\mathrm{B}$ ). This reaction is found in patients with thromboangiitis obliterans, arteriosclerosis, or arterial embolism. It is not influenced by the presence or absence of intermittent claudication. In obstruction of the arteries of the lower extremities intermittent claudication will sooner or later appear if the exercise is great enough, but the exercise tonoscillography is abnormal much sooner than the clinical symptoms of intermittent claudication appear. Therefore, oscillography after exercise can be used to diagnose organic arterial disease in an early stage with only uncertain or no subjective symptoms, and before other signs of arterial disease have appeared. The coarctation patients sometimes present the symptoms of intermittent claudication, and before the first operation had been performed Ejrup showed that they were subject to a pathological reaction from the lower limbs when at work, just as are patients with organic alterations in the peripheral arteries (Plate IV $b-\mathrm{C}$ ).

The oscillographic records are taken with an automatic graphically registering bloodpressure recorder (Ejrup, 1944). A series of oscillograms is recorded vertically on the same paper. The registration is automatic; a new oscillogram is started every $30 \mathrm{sec}$. and takes about $20 \mathrm{sec}$., and after a pause of a few seconds the next begins. During that pause the cuffs are completely emptied so that no venous congestion can take place. Usually a two-cuff system has been used, but the one-cuff is also applied. The reading of the systolic and the diastolic pressure levels differs in the two systems. Using the two-cuff system, where one is placed around the calf and the other around the ankle, the pressure increases steadily in the higher (pressure) cuff during the taking of the record, whereas the lower (recording) cuff is inflated to a certain constant pressure, for example $50 \mathrm{~mm}$. $\mathrm{Hg}$. The advantage of this system is that the curves are more regular and thus easier to compare, and the systolic blood pressure can be better read. The pulsations which get through the artery beyond the proximal cuff are registered from the lower cuff. The pressure variations in the pulse-cuff are converted to electric potential variations with a piezoelectric crystal and amplified. The slight pulsations that are found in pathological cases can, in this way, easily be revealed. The apparatus has been especially useful because it registers the conditions of the blood pressure and pulsations after exercise.

The cause of the "inverse reaction" in work tests is a matter for speculation. Is it arterial spasm, especially in the collaterals, or a physiological compensatory constriction, or is it the emptying of the blood stores of the extremities into the intact venous system, in combination with insufficient supply? Since the time for recovery in patients with organic changes in the arteries can be as long as 
half an hour or more, it seems likely that the artery or collaterals are in a state of abnormal spastic constriction. During an experiment, the pulsations are sometimes observed to decrease further with increased subjective symptoms; and sometimes, for several minutes after work, no pulsations at all are registered, and then during one or two minutes full deflections can be obtained.

If a work test is carried out with the upper limbs and upper body (trunk) with simultaneous oscillography from the lower limbs, we find that in patients suffering from coarctation the pulsations decrease and become hardly noticeable (Plate $\mathrm{Va}$ ). A collateral spasm or a compensatory contraction of the arteries distal to the stenosis probably occurs after work in coarctation of the aorta, and the supply of blood is probably decreased not only in the lower limbs but everywhere below the aortic stenosis. This may affect renal function, giving rise to a Goldblatt mechanism because of the development of relative ischaemia in the kidneys after exercise.

The circulation returns to normal more or less rapidly after operation. The blood pressure rises in the lower limbs and the pulsations increase in size. In the upper part of the body these effects are reversed, and examinations after the operation give a completely normal response to work both in the upper and in. the lower limbs. In one patient (case 2 ), $4 \frac{1}{2}$ months after operation there were no improved pulsations but only a rise in blood pressure after exercise, and this might indicate that the restoration was not quite successful. Eighteen months after operation a distinct improvement was found even in this patient, and two out of eight exercise-tests were normal. The exercise-tests carried out on the three other patients who were examined more than 1 year after operation gave normal results. One of these is shown in Plate $\mathrm{Vb}$; the others were similar.

The cerebral circulation is greatly relieved by the post-operative drop in blood pressure both at rest and after exercise (Ejrup, 1944). The blood pressure was measured in the arms and in the legs after the same exercise before and after operation (Table III). One of our patients (case 3) had, before operation,

TABLE. III

BLOOD PRESSURE IMMEDIATELY AFTER THE SAME EXERCISE BEFORE AND AFTER OPERATION

\begin{tabular}{|c|c|c|c|c|c|c|}
\hline & & & & & Before operation & After operation \\
\hline Case 1 & $\therefore$ & . & . & $\begin{array}{l}\text { Arm } \\
\text { Leg }\end{array}$ & $\begin{array}{c}230 / 115 \\
75 / ?\end{array}$ & $\begin{array}{l}180 / 90 \\
180 / 90\end{array}$ \\
\hline Case 2 & . & $\therefore$ & $\cdots$ & $\begin{array}{l}\text { Arm } \\
\text { Leg }\end{array}$ & $\begin{array}{r}185 / 90 \\
95 / 70\end{array}$ & $\begin{array}{l}175 / 85 \\
155 / 70\end{array}$ \\
\hline Case 3 & $\cdots$ & . & $\cdots$ & Arm & $\begin{array}{l}280 / 120 \\
125 / 90\end{array}$ & $\begin{array}{l}220 / 100 \\
230 / 110\end{array}$ \\
\hline Case 4 & $\cdots$ & $\cdots$ & $\cdots$ & $\underset{\text { Leg }}{\text { Arm }}$ & $\begin{array}{c}275 / 135 \\
85 / 60\end{array}$ & $\begin{array}{l}230 / 90 \\
200 / 100\end{array}$ \\
\hline
\end{tabular}


a blood pressure of $280 / 120 \mathrm{~mm}$. $\mathrm{Hg}$ in the upper extremities after exercise : after operation the blood pressure rose to $220 / 100$ after the same exercise. In this instance the effect in the lower limbs is even more striking; a pre-operative level of 125/90 was increased to a post-operative level of $230 / 110 \mathrm{~mm}$. $\mathrm{Hg}$.

\section{RADIOLOGICAL StUdies}

In the adult form of coarctation of the aorta changes in the ribs, the heart, different parts of the thoracic aorta, the oesophagus, and in the outlines of the superior and posterior mediastinum have been described. These are as follows.

The changes in the ribs (Plate VI) consist of a widening of the costal sulci and of bilateral long or punched-out defects of the lower edges of the ribs. (Railsback and Dock, 1929 ; Roesler, 1928 ; Fray, 1930.) These are caused by pulsations in the dilated, elongated, and consequently tortyous intercostal arteries which form a considerable part of the collateral circulation. The notchings are neither constant nor pathognomonic; they have occasionally been observed in disease of the aortic and mitral valves and in cases with essential hypertension.

The changes in the shape of the heart are characteristic of those found in hypertension. Enlargement of the left ventricle and increased amplitude of the pulsations are often but not constantly found. The curve of the ascending aorta to the right may be increased by the pre-stenotic hypertension (Fray, 1930; Schatzki and Hallerman, 1930 ; Shanks and others, 1938).

The aortic arch is difficult and often impossible to demonstrate and the adjacent part of the descending aorta is also difficult or impossible to see; the aortic knuckle is small or absent (Fray, 1930 ; Railsback and Dock, 1929 ; Schatzki and Hallermann, 1930; Shanks and others, 1938). These findings, together with the invisibility of the descending part of the arch, due to defect or discontinuity, should be pathognomic (Fray, 1930).

The superior mediastinum is widened and pulsates vigorously, especially to the left ; the widening must be caused by arteries. The outline of its left border is convex laterally (Schatzki and Hallermann, 1930 ; Assmann, 1934), and it has been suggested that this is caused by an aneurysmal widening of the pre-stenotic part of the aorta or of the origin of one of the great vessels (Schatzki and Hallermann, 1930). In one case it was found to be produced by the widened origin of the left subclavian artery (Assmann, 1934). The widened left subclavian artery produces a marked impression on the oesophagus (Shanks and others, 1938).

The posterior mediastinum shows an indentation of barely one centimetre in depth approximately on a level with the fifth dorsal vertebra, and at the same level there may be a bulge of the oesophagus to the left. Both these changes are directly due to the coarctation (Wolke, 1937). 
These descriptions of the radiographic picture of coarctation of the aorta in our opinion show some contradictions and are incomplete in several respects. What are the anatomical bases for the outline of the left border of the superior mediastinum, the indentation to the right of the left lateral margin of the posterior mediastinum, and the reduced or eliminated visibility of the aortic arcl. as far as the area of coarctation? Which changes are constant and which are pathognomonic?

The following additional details are of importance. The cranial boundary of the aortic arch is situated approximately on a level with the indentation in the left border of the superior mediastinum (Plate VIIa). Consequently the aorta can be the basis of only the caudal part of this indentation. This is evident also from the fact that the characteristic aortic arch impression on the oesophagus is situated on a level with this part (Plate VII b).

In most cases of coarctation of the aorta the descending portion of the arch is situated more caudally and medially than -usual, that is, in close proximity to the left tracheo-bronchial angle (Plate VIII). The arch, when riding over the left main bronchus, often pulls this structure down a little so that the bronchus leaves the trachea at a more acute angle than usual. In the $3 r^{-}$cases the aortic arch impression on the oesophagus is situated more caudally than normally and, with the left bronchus impression, is fused to a single curve which is not longer than the normal aortic arch impression. Hypertension generally gives rise to unfolding of the aortic arch, but in coarctation the arch is short ; the cause of this shortness is made clear by the morbid anatomy.

In one of our cases the left border of the superior mediastinum was a straight line ; in the others it was S-shaped with a convexity to the left above the indentation (Plates VII $a$ and VIII). The radiological picture suggests that the S-shape is caused by the dilated left subclavian artery (Plate IXb); it is at the same level as the impression on the oesophagus caused by this vessel (Plate VIII).

\section{Correlation of RADIOGRaPhic and Operation Findings}

\section{Left subclavian artery}

At operation, the left subclavian artery is much dilated and strongly pulsating. It is prominent from the rest of the mediastinum, especially at its origin. It generally forms the cranial part of the indentation dorsally and to the left in the mediastinum. In one case a slightly aneurysmal pre-stenotic portion of the arch took part in its formation. The caudal part is formed by the aorta below the level of the left subclavian artery. The site of this indentation is identical with that observed radiologically.

\section{Coarctation}

The coarctation can be located immediately or at some distance below the origin of the left subclavian artery. It is usually bridged over by pleura and 
subpleural connective tissue so that its exact site and distance from the left subclavian artery cannot be decided before the pleura has been opened and the coarctation dissected out. The coarctation at the insertion of the ductus arteriosus ligament and the adjacent parts of aorta are drawn medially and ventrally by this ligament and by the narrowing of the aorta, so that an extra, V-shaped curve with its tip in the mediastinum develops on the aorta. This extra curve, and the longitudinal narrowing in the conically coarctated portions, cause a tautness of the aorta. Below the coarctation the pulsations are very weak and the pressure extremely low. The arch, and especially its descending portion, is dislocated caudally and medially so that its concavity is nearer than normal to the left bronchus. In two cases the correctness of the radiological observations that the aortic arch impression may be dislocated caudally and fused with the left bronchus impression was verified at operation. Consequently the indentation in the left border of the posterior mediastinum indicates the origin of the left subclavian artery from the aorta. It is not essentially a direct sign of the coarctation, which must be situated at or caudally to this point. The correctness of this interpretation has been verified operatively (Plate Ia). In one case only, a second indentation situated caudally to the one described above was seen and interpreted as the coarctation itself (Plate IXb) ; but in the majority of our cases the stenosis was not directly visible, and the distance from the left subclavian artery could not be immediately decided. The resection of the stenotic part of the aorta is technically easier if this distance is large; it may therefore be of practical value to be able to decide it by means of radiographs.

The reduced or eliminated visibility of the aortic arch and the descending aorta is not a constant feature. When present, it is due to the reduction of the normal windings of the aorta (Plate I $a$ ). The earlier interpretation, that the invisibility of the arch was due to a defect or discontinuity in the vessel and thus that it was pathognomonic of coarctation, is not in agreement with the morbid anatomy (Plate IXa), and, moreover, would not explain the reduced visibility of the other parts of the aorta. Furthermore, extremely small aortic knuckles without visible arch in oblique and lateral radiographs are to be found in many subjects, especially children, in whom there are no circulatory disturbances. In these normal subjects the invisibility of the descending portion of the aortic arch is only an expression of variation in the length of the aorta and in the extent of its windings.

\section{The oesophagus}

The oesophagus normally regains its ordinary width to the left above the aortic arch impression so that it presents a seeming bulge to the left at the level of the aortic arch (Plate VII $b$ ). In coarctation of the aorta the site and length of this bulge is modified between the altered aortic arch impression and the left subclavian artery impression (Plate VIII). It is situated above the coarctation, on 
a level with the indentation between the left subclavian artery and the aorta, Thus it is not a direct sign of the coarctation. It indicates a space behind the summit of the aortic arch between the descending portion of the arch and the left subclavian artery. If the oesophagus crosses the aortic arch in the plane of the origin of the left subclavian artery, the impressions of the aortic arch and of the subclavian artery are fused into a single elongated curve, and this bulge is not seen (Plate IXc).

The outline of the right border of the superior mediastinum on a level with the clavicle is inconstant and can rarely be interpreted as due to an enlarged innominate artery.

The left auricle as well as the left ventricle may be enlarged (Plate VIII).

The frequency of the changes in the radiological picture indicated above is shown in Table IV and was verified at operation.

TABLE IV

INCIDENCE OF RADIOGRAPHIC CHANGES IN SEVEN CASES OF COARCTATION OF THE AORTA

\begin{tabular}{|c|c|c|c|c|c|c|c|c|c|}
\hline & Case No.: & 1 & 2 & 3 & 4 & 5 & 6 & 7 & Frequency \\
\hline \multirow{2}{*}{\multicolumn{2}{|c|}{$\begin{array}{l}\text { Heart volume per sq. m. (before } \\
\text { operation (ml.)) } \\
\text { Body surface (after operation } \\
\text { (ml.)) }\end{array}$}} & 380 & 620 & 355 & 400 & 355 & 365 & 710 & \\
\hline & & 320 & 465 & 355 & * & * & * & * & \\
\hline \multirow{3}{*}{\multicolumn{2}{|c|}{$\begin{array}{l}\text { Enlargement of left ventricle } \\
\text { Enlargement of left auricle } \\
\text { Increased curve of ascending } \\
\text { aorta }\end{array}$}} & - & + & - & - & - & - & + & $2: 7$ \\
\hline & & - & + & - & - & - & + & - & \\
\hline & & - & + & - & - & - & - & - & $1:$ \\
\hline \multicolumn{2}{|c|}{$\begin{array}{l}\text { Dislocation of aorta towards } \\
\text { mediastinum }\end{array}$} & + & + & + & + & + & - & + & $6: 7$ \\
\hline \multirow{2}{*}{\multicolumn{2}{|c|}{$\begin{array}{l}\text { Shortness of aorta } \\
\qquad \begin{array}{l}\text { S-curved outline of } \\
\text { left border of } \\
\text { superior medi- } \\
\text { astinum }\end{array}\end{array}$}} & + & $\stackrel{+}{+}$ & $\bar{t}$ & + & $\bar{t}$ & + & $\stackrel{+}{+}$ & $\begin{array}{l}5:: 7 \\
7: 7\end{array}$ \\
\hline & & * & + & + & + & + & + & + & $6: 6$ \\
\hline \multirow{2}{*}{$\begin{array}{l}\text { Widened } \\
\text { left } \\
\text { subclavian } \\
\text { artery }\end{array}$} & $\begin{array}{l}\text { Indentation in } \\
\text { posterior medi- }\end{array}$ & + & + & + & + & + & + & + & $7: 7$ \\
\hline & $\begin{array}{l}\text { astinum } \\
\text { Modified bulge in } \\
\text { left border of } \\
\text { oesophageal out- } \\
\text { line of level of }\end{array}$ & * & + & + & + & + & + & + & $6: 6$ \\
\hline \multirow{3}{*}{\multicolumn{2}{|c|}{$\begin{array}{l}\text { Increased pulsation of left sub- } \\
\text { clayian artery } \\
\text { Decreased pulsation of descend- } \\
\text { ing aorta } \\
\text { Erosions of ribs .. .. } \quad . .\end{array}$}} & + & + & + & + & + & + & + & $7: 7$ \\
\hline & & + & + & + & + & + & + & + & $7: 7$ \\
\hline & & + & + & - & + & + & - & + & $5: 7$ \\
\hline
\end{tabular}

1 Estimated radiographically. $+=$ present. $-=$ absent. $*$ not examined. 
To summarize the radiological observations: in coarctation of the aorta there are constant, or essential, as well as inconstant radiographic changes. The only changes which are pathognomonic are:

1. Widening of the left subclavian artery, visible as

(a) an S-curved outline of the left border of the superior mediastinum,

(b) an impression upon the oesophagus,

(c) an indentation of the left border of the posterior mediastinum,

(d) a modification of the impression of the aortic arch upon the oesophagus.

2. The discrepancy between the increased pulsations in the left subclavian artery and the decreased pulsations in the adjacent part of the descending aorta.

Inconstant changes are widening of the costal sulci, shortening of the aorta, widening of the innominate artery, and enlargement of the left auricle. The reduced visibility of the descending aorta is neither constant nor pathognomonic.

\section{SUMMARY}

1. The reasons which led to operative treatment of certain patients suffering from coarctation of the aorta are discussed.

2. An account is given of the operative technique which has been used by Crafoord to remove the stenotic part of the aorta and to restore continuity by end-to-end anastomosis.

3. Up till the end of 1946,15 patients had been submitted to this operation, with good results in 11. Two patients died as a result of the operation, and two others (who are not included in this series) were explored but in them the coarctation could not be removed.

i. The historical aspects of the subject are reviewed.

5. The symptomatology and diagnosis are described, and special stress is laid upon the value of oscillographic studies in the investigation of these patients and in assessing their post-operative progress.

6. The radiological appearances of coarctation of the aorta are described. The features which have been considered as pathognomonic by other investigators are reviewed, and to these are added certain additional observations.

\section{REFERENCES}

Abbott, Maud E. (1931). Nelson's Loose Leaf Medicine, 4, 207.

Andreesen, R. (1929). Beitr. path. Anat., 82, 433.

Ask-Upmark, E. (1942). Acta med. scand., 112, 7.

Assmann, H. (1934). Die klin. Röntgendiagnostik d. inn. Erkrankungen, Teile I, Berlin, Vogel.

Blalock, A., and Park, E. A. (1944). Ann. Surg., 119, 445. 
Blalock, A., and Taussig, H. B. (1945). J. Amer. med. Ass., 128, 189.

Blumenthal, S., and Davis, D. B. (1941). Amer. J. Dis. Child., 62, 1224.

Bodlander, J. W. (1946). Amer. Heart J., 31, 785.

Bourne, G. (1946). Brit. med. J., 1, 609.

Briesemeister, W. (1942). Munch. med. Wschr., 89, 738.

Brotchner, R. J. (1939). Arch. Path., 28, 676.

Crafoord, C. (1938). Suppl. to Acta chir. scand.

Crafoord, C. (1939). Nord. med. Tidskr., 14, 1043.

Crafoord, C. (1940). J. thorac. Surg., 9, 237.

Crafoord, C. (1945). Nord. Med., $26,864$.

Crafoord, C., Anderson, E., and Frenckner, P. (1939). Acta otolaryng. Stockh., 28.

Crafoord, C., and Nylin, G. (1945). J. thorac. Surg., 14, 347.

Eisenberg, G. (1938). J. Pediat., 13, 303.

Ejrup, B. (1944). Nord. Med., 23, 1770.

Ejrup, B. (1945). Nord. Med., 27, 1498.

Ejrup, B. (1946). Nord. Med., 29, 327.

Evans, W. (1933). Quart. J. Med., N.S., 2, 1.

Fray, W. W. (1930). Amer. J. Roentgen., 24, 349.

Gladnikoff, H. (1946). Acta radiol., $27,8$.

Grishman, A., Steinberg, M. F., and Sussman, M. L. (1941). Amer. Heart J., 21, 365.

Grishman, A., Sussman, M. L., and Steinberg, M. F. (1944). Amer. Heart J., 27, 217.

Gross, R. E. (1945). Surgery, 18, 673.

Gross, R. E., and Hufnagel, C. A. (1945). New Engl. J. Med., 233, 287.

Hamilton, W. F., and Abbott, M. E. (1928). Amer. Heart. J., 3, 381.

King, J. T. (1937). Ann. intern. Med., 10, 1802.

Laubry, C., and Heim de Balsac, R. (1937). Arch. Mal. Caur, 30, 963.

Laubry, C., and Pezzi, C. (1921). "Traité des Maladies Congénitales du Cœur," J. B. Baillière. Paris.

Levine, S. A. (1940). "Clinical Heart Disease," 2nd edit. New York. Saunders.

Liljestrand, G., Lysholm, E., Nylin, G., and Zachrisson, C. G. (1939). Amer. Heart J., $17,406$.

Linell, F. (1945). Nord. Med., 28, 2555.

Love, W. S., jun., and Holms, J. H. (1939). Amer. Heart J., 17, 628.

Nylin, G. (1938). Acta med. scand. Suppl., 93, 1.

Paris (1789). J. Dessult, 2, 107.

Perlman, L. (1944). Amer. Heart J., 28, 24.

Railsback, O. C., and Dock, W. (1929). Radiology, 12, 58.

Roesler, H. (1928). Wien. Arch. inn. Med., 15, 521.

Roesler, H. (1943). "Clinical Roentgenology of the Cardiovascular System," 2nd edit. P. 398. Charles C. Thomas, Springfield III.

Schatzki, R., and Hallermann, W. (1930). Fortschr. Geb. Röntgenstr., $42,324$.

Shanks, S. C., Kerley, P., and Twining, E. W. (1938-39). "A Textbook of $X$-ray Diagnosis." London. 3 vols. Lewis.

Steinberg, M. F., Grishman, A., and Sussman, M. L. (1943). Amer. J. Roentgen., 49, 766.

Steinberg, M. F., Grishman, A., and Sussman, M. L. (1943). Amer. J. Roentgen., 50, 306.

Stewart, H. J., and Bailey, R. L., jun. (1941). J. clin. Invest., 20, 145.

Stewart, H. J., Haskell, H. S., and Evans, W. F. (1944). Amer. Heart J., $28,217$.

Sussman, M. L., Steinberg, M. F., and Grishman, A. (1941). Amer. J. Roentgen., 46, 745.

Wadstein, E. (1897). "Stenos och Obliteration af Aorta vid eller i närheten af Ductus Botali." Lund, E. Malmstrø̋.

Wolke, K. (1937). Acta radiol., 18, 319. 


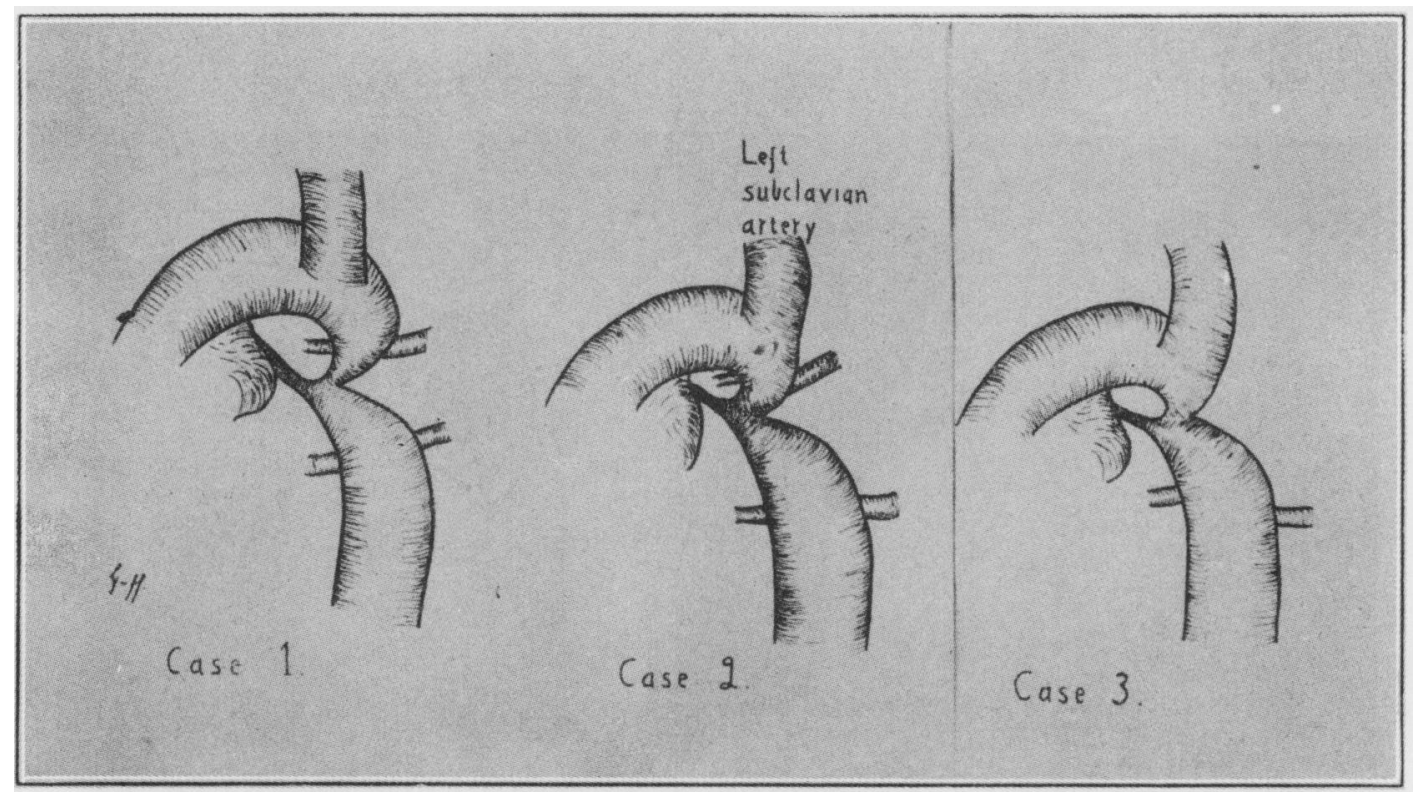

PLATE Ia.-Schematic drawings of the conditions found at operation in the first three operated cases of aortic coarctation.

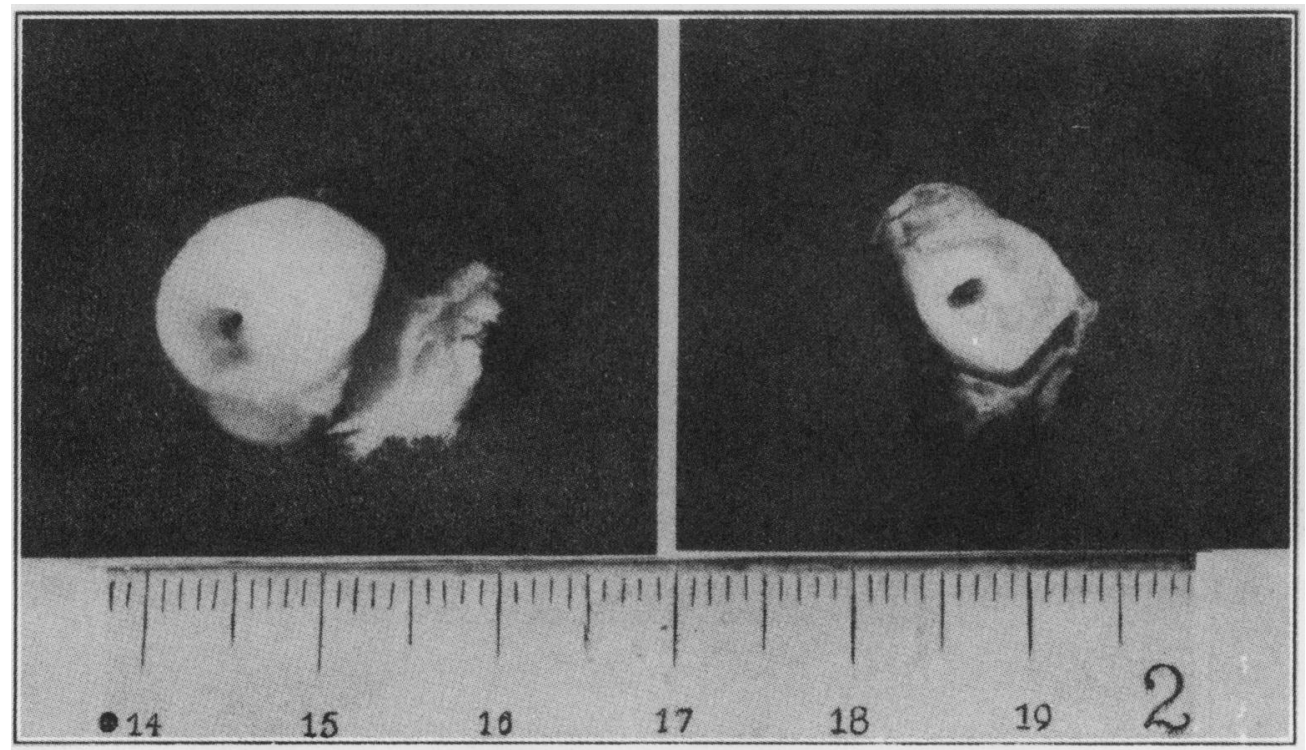

Plate Ib.-Aortic coarctation. Specimens removed from two patients. 




PLATE II.-Antero-posterior and lateral radiographs to show the heart size before (above) and after (below) operation. Note the diminution in size. 


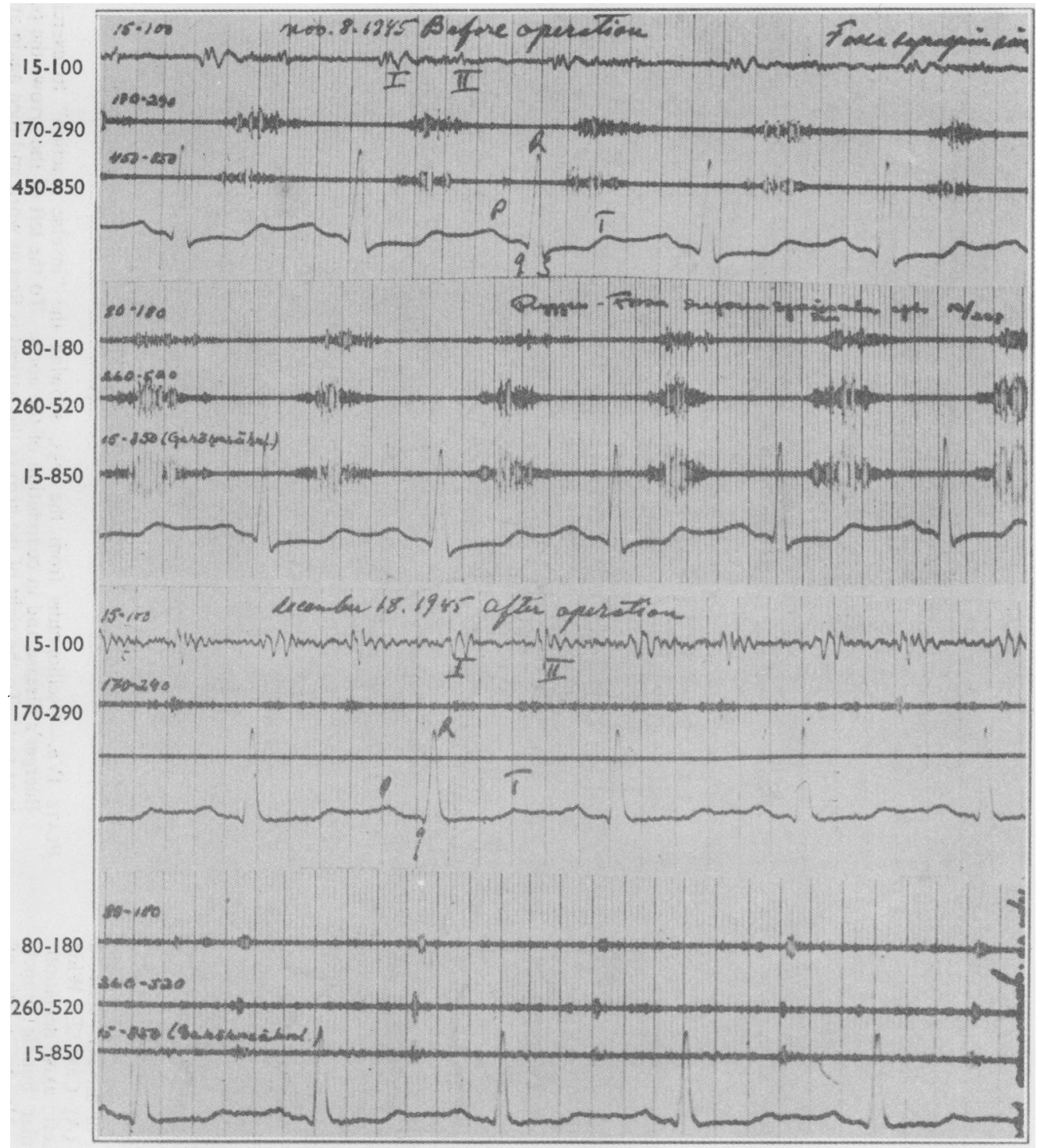

Plate Ill.-Phonocardiograms from case 6 before and after operation, with simultaneous electrocardiograms (lead II). The sounds over a collateral vessel in the left supraspinatus fossa are registered. The figures to the left of the tracings represent the frequency ranges in cycles per second. There is a rough systolic murmur beginning very late in systole, disappearing after operation.

$\mathbf{K}$ 

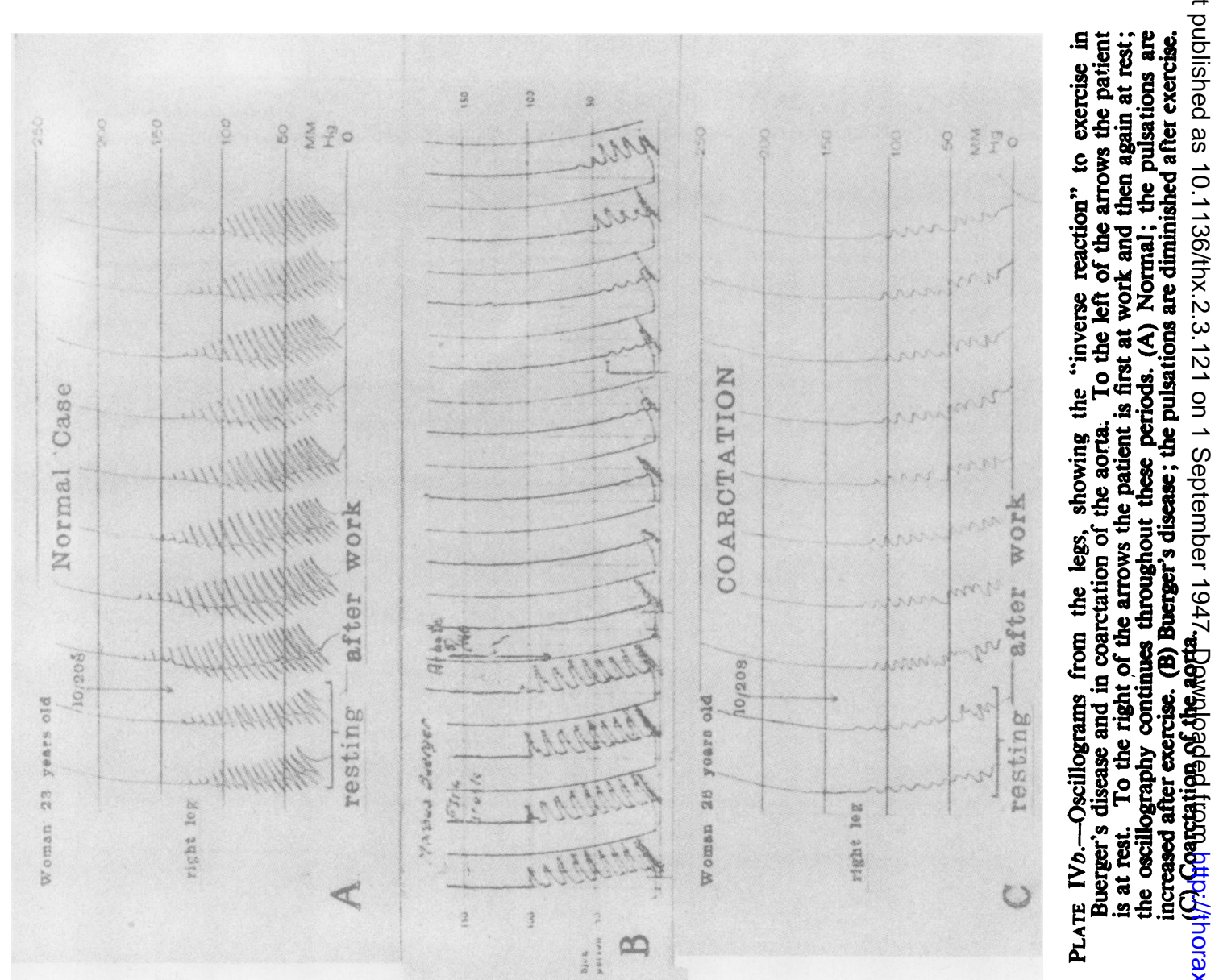

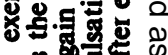

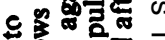
O

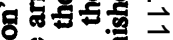
影宂前

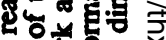

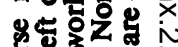

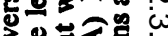
影递 0 色然

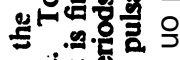
울

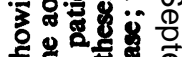

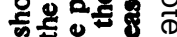
능

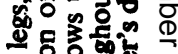

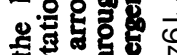
至 ถั่

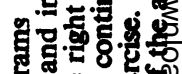

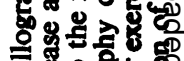

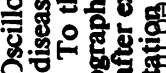
个象象 8 之总果家

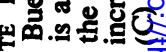

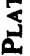

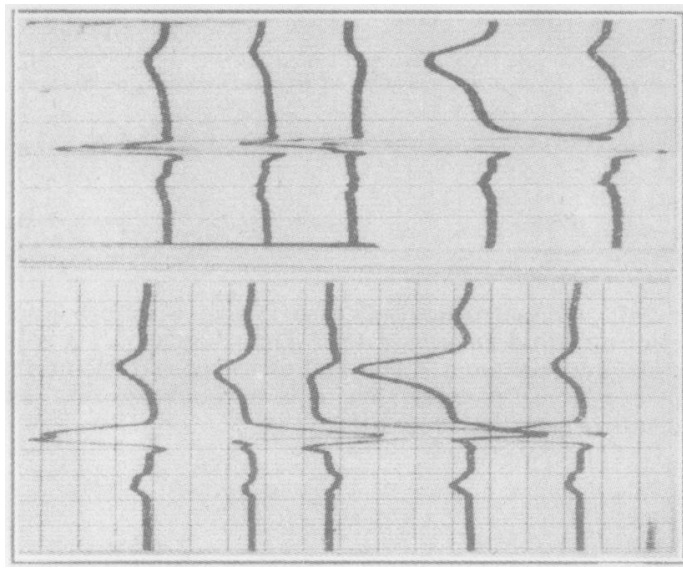

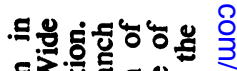

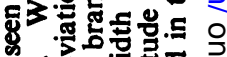

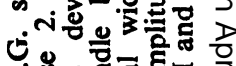

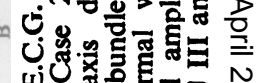

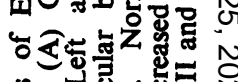
\% 矛。氙 N

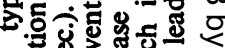

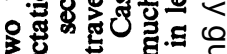

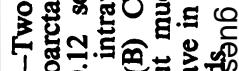
1. 8̊. 之.

s 

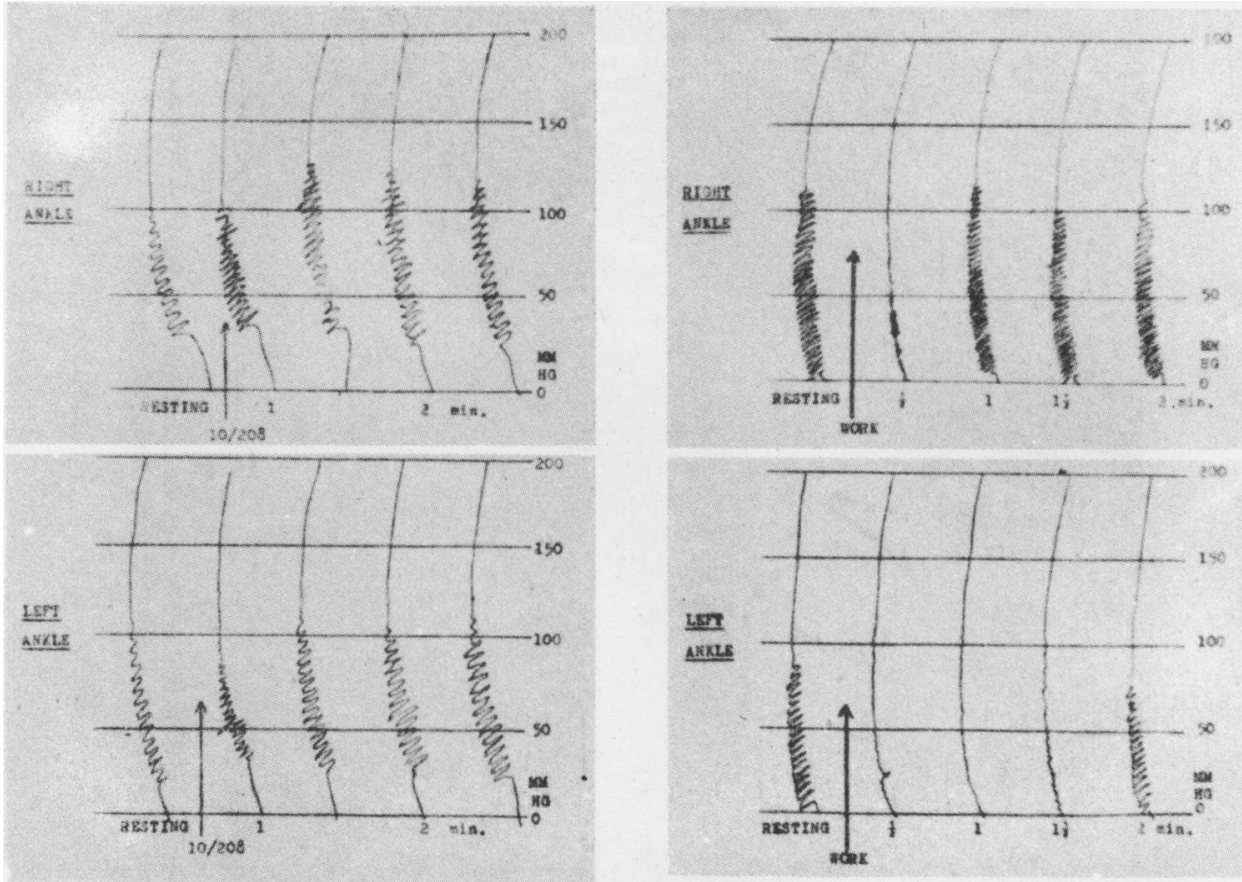

Plate Va.-Oscillograms from the legs in a case of coarctation of the aorta, showing the effect of exercise with the legs (on the left) and with the arms (on the right). There is gross diminution in the pulsations after exercise with the arms.

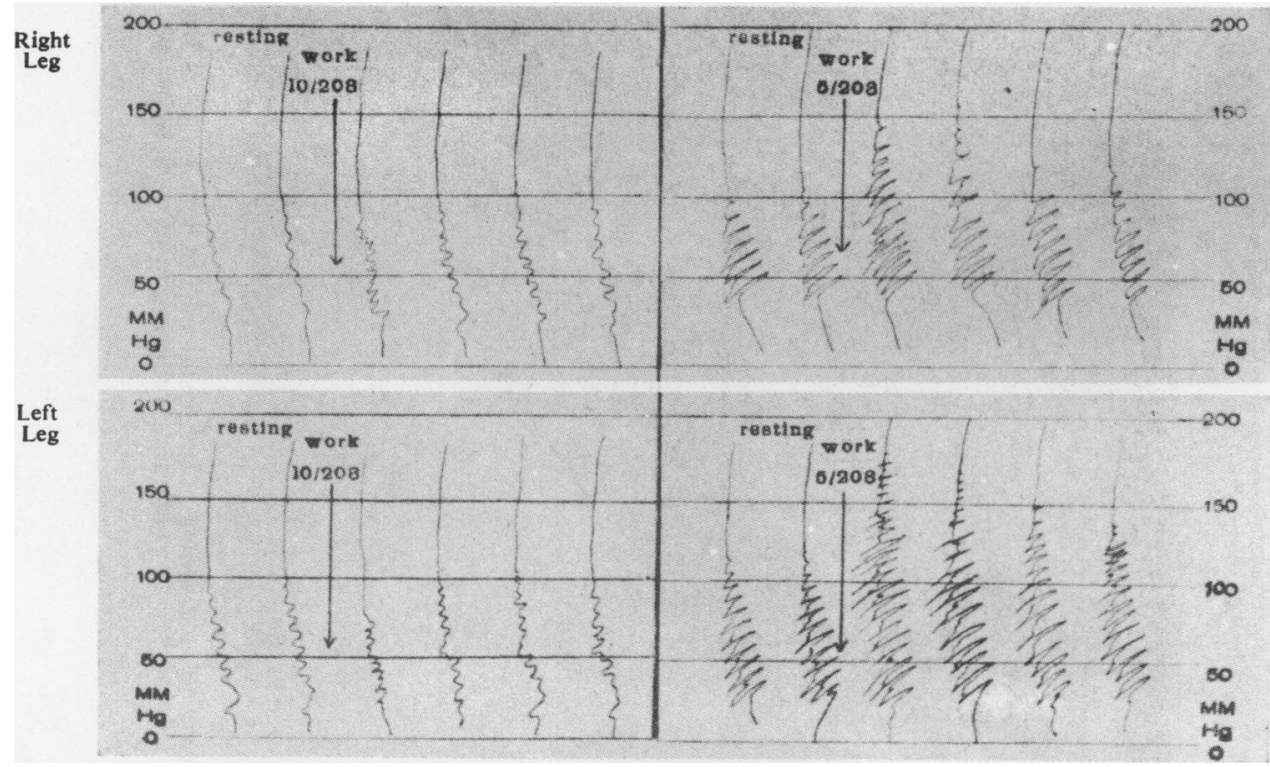

Plate Vb. - Case 1. Oscillography after exercise. To the left from right and left leg before operation. To the right from right and left leg one year after operation. After operation there are bigger pulsations at rest, and a good reaction to exercise. An
exactly similar response was found in two other cases re-examined one year after operation. 

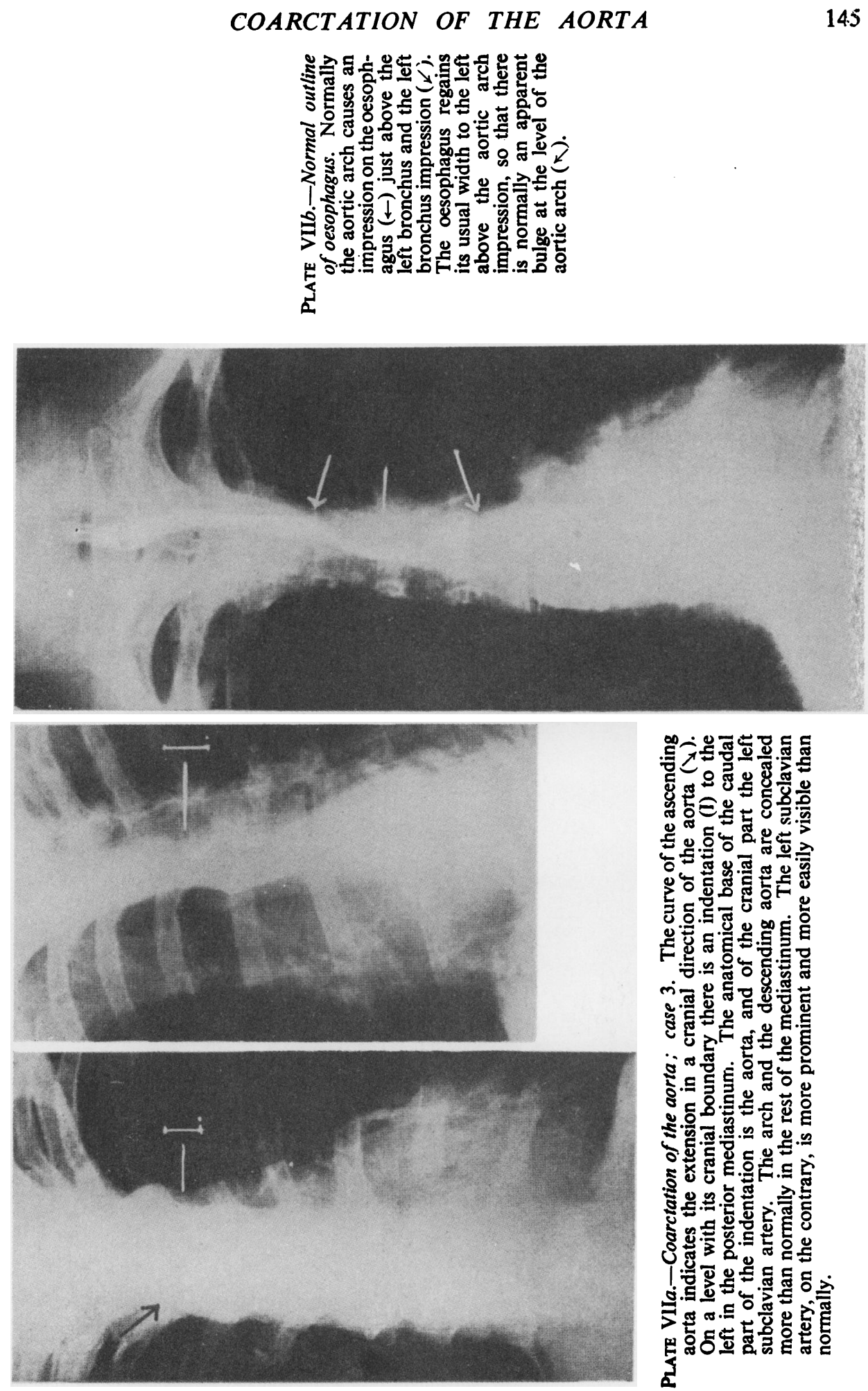


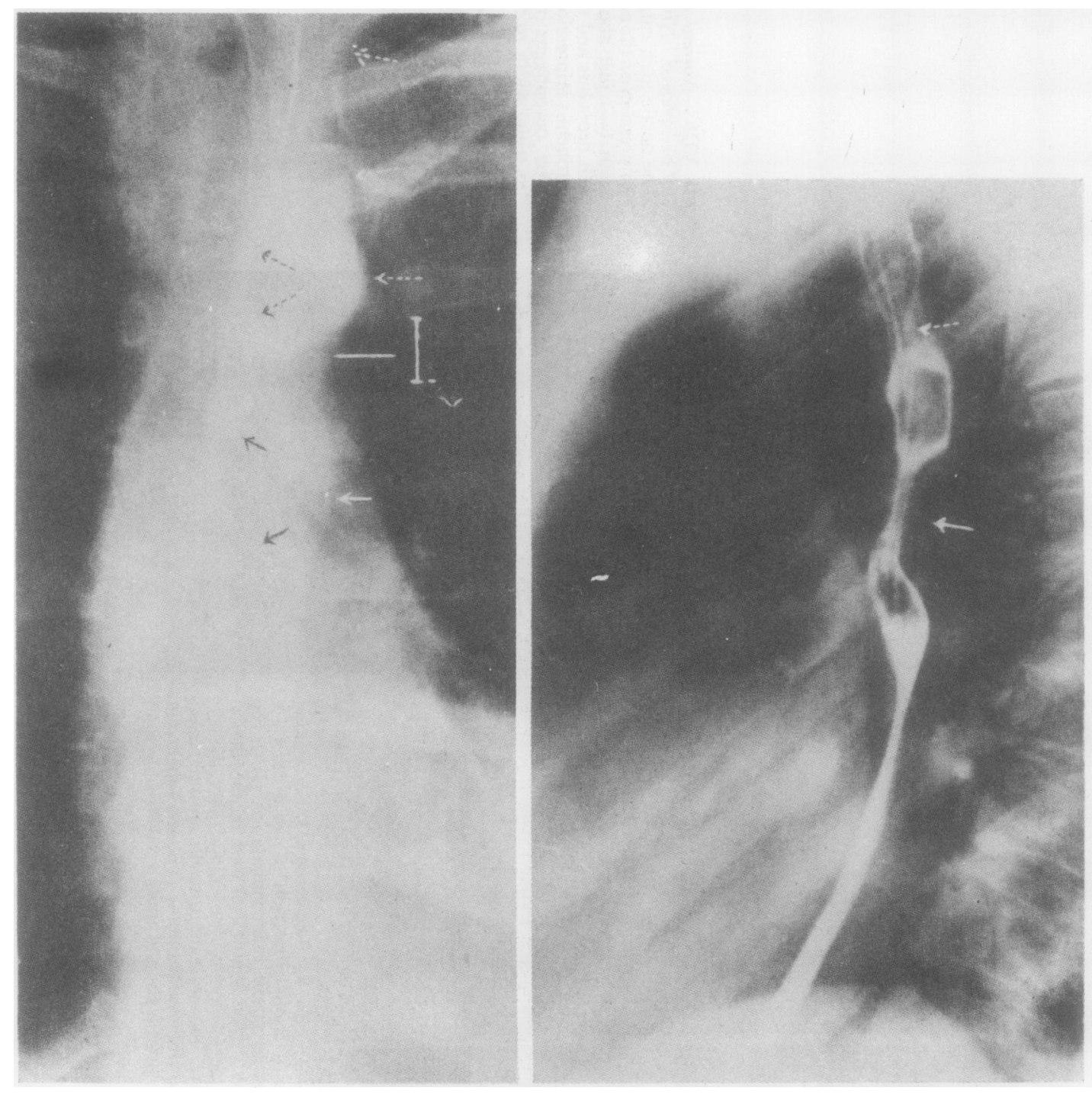

PLATE VIII.-Coarctation of the aorta. Dotted arrows: The impression on oesophagus and the outline of the left subclavian artery. Unbroken arrows : Impression on oesophagus and outline of the descending portion of the aortic arch. The aorta is shortened; the whole arch is displaced caudally in closer proximity to the left bronchus than is usually the case, and the aortic arch impression on the oesophagus is fused with the impression of that part of the left bronchis near the tracheal bifurcation. 

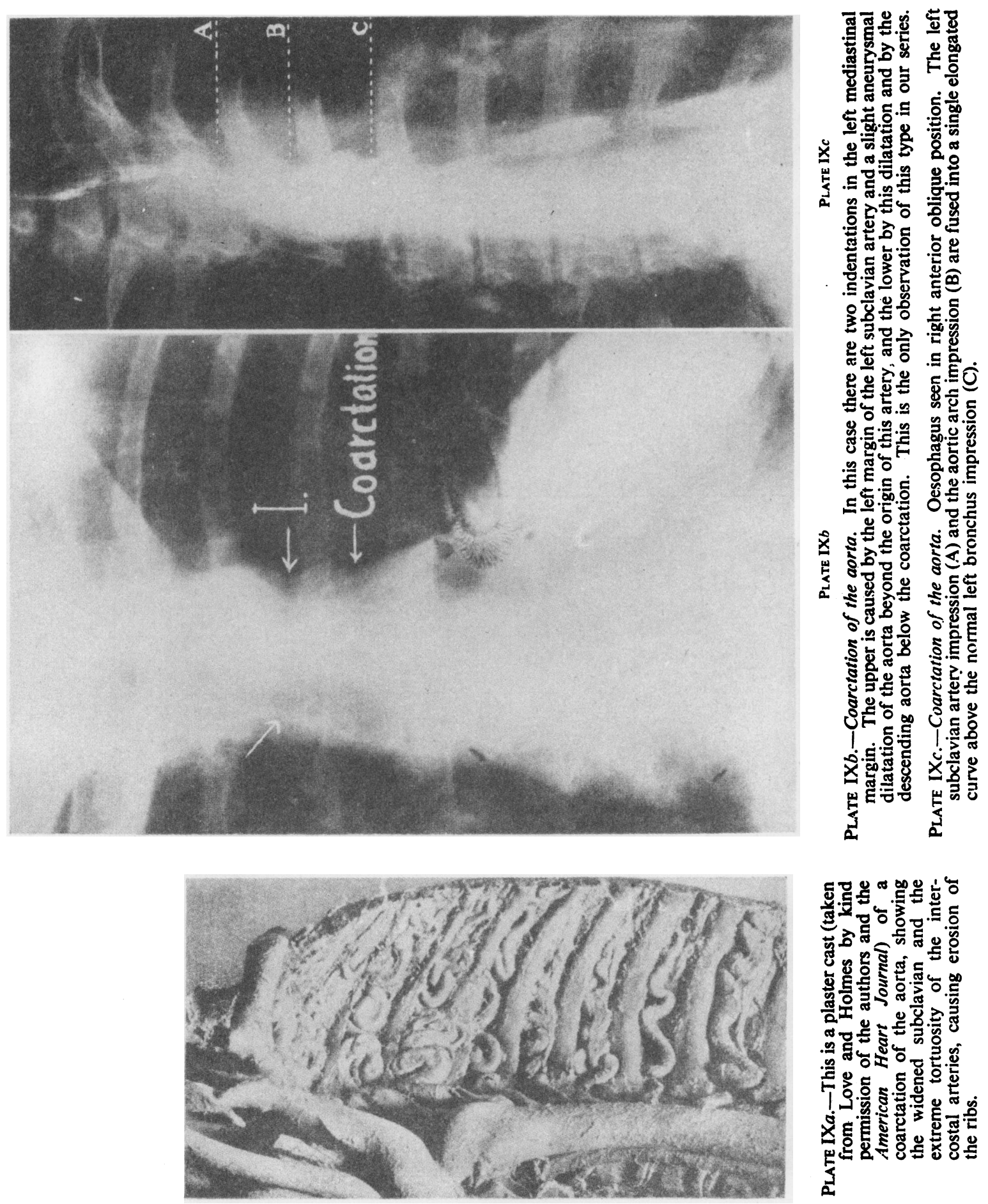

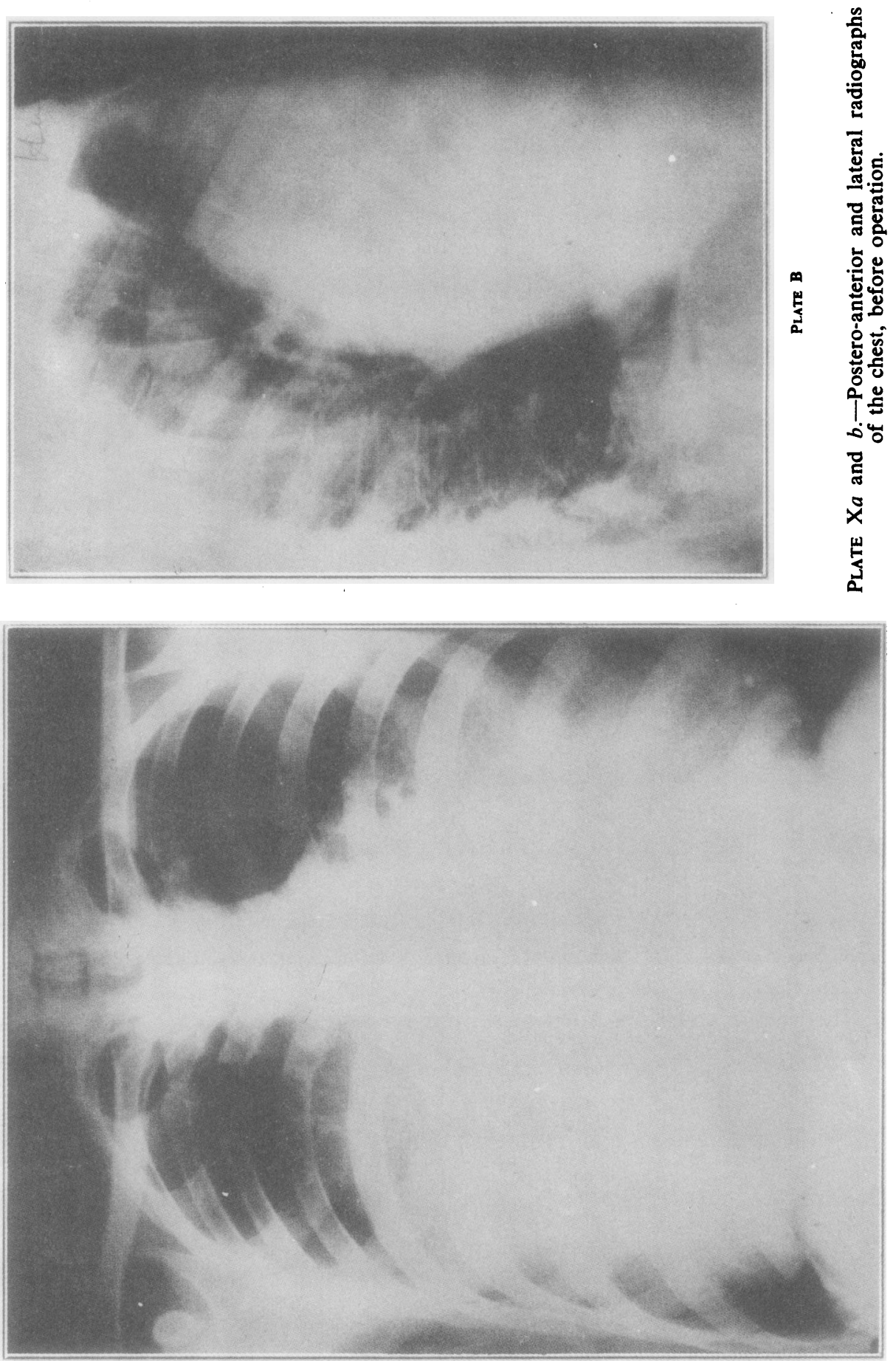


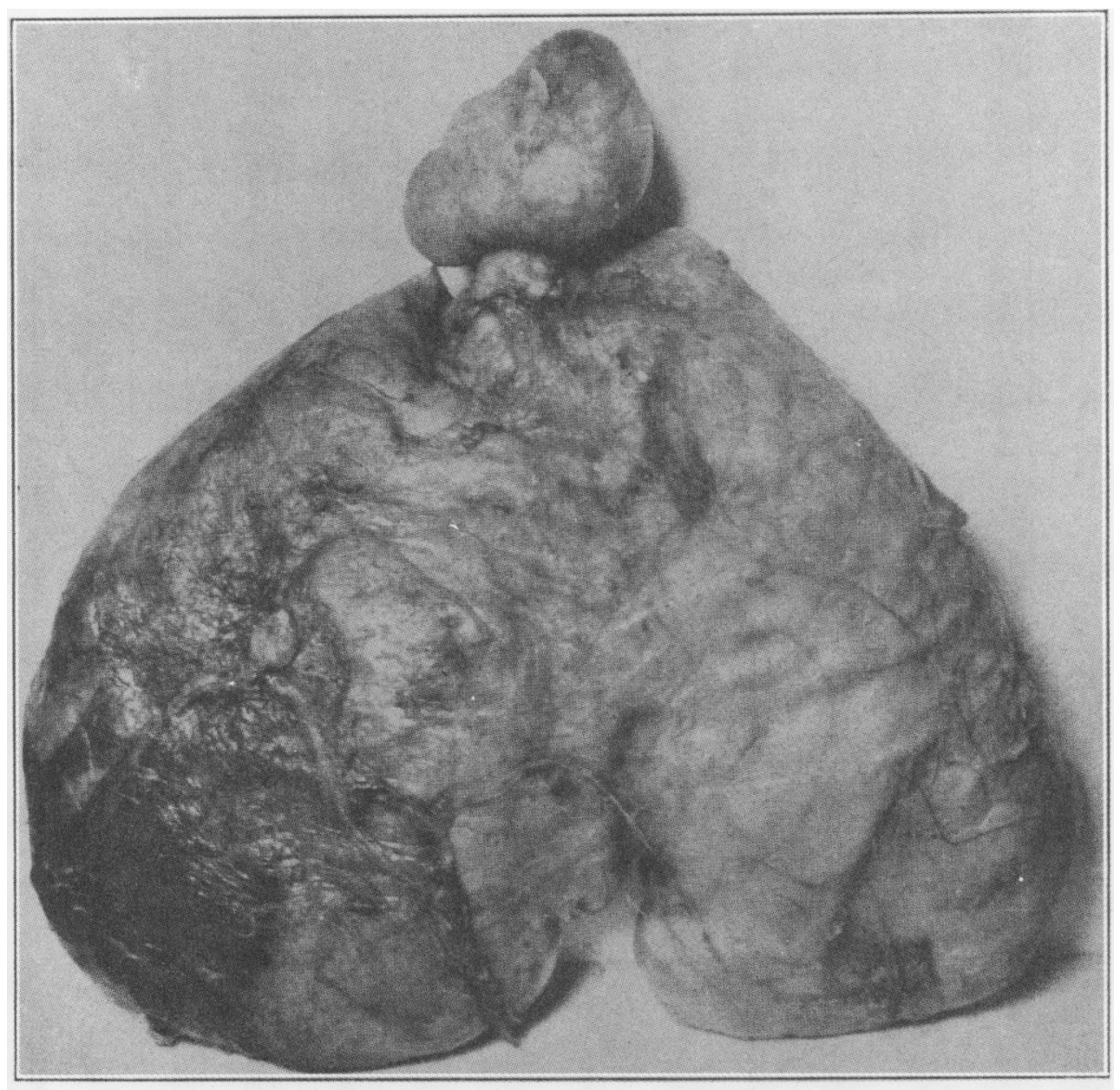

Plate XI.-The tumour. 


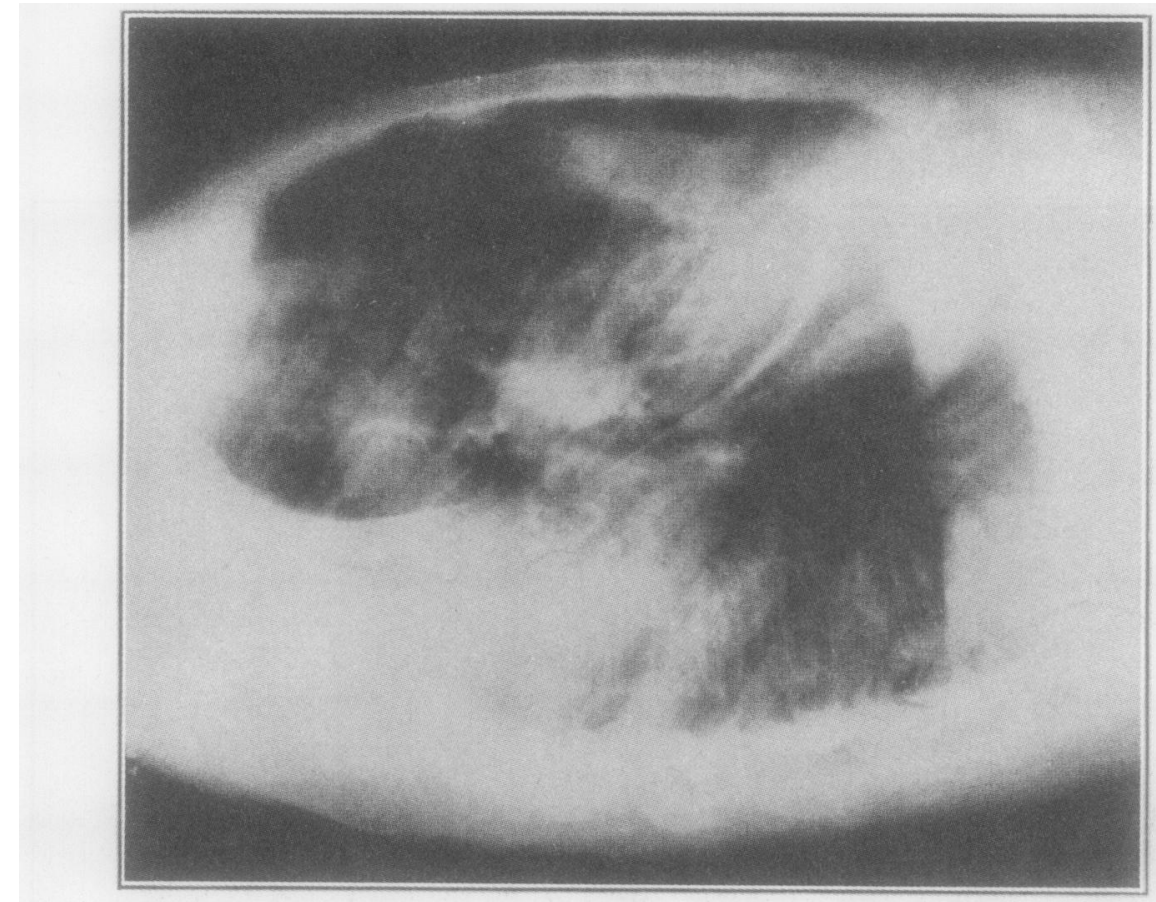

茨

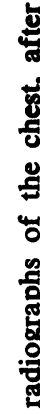

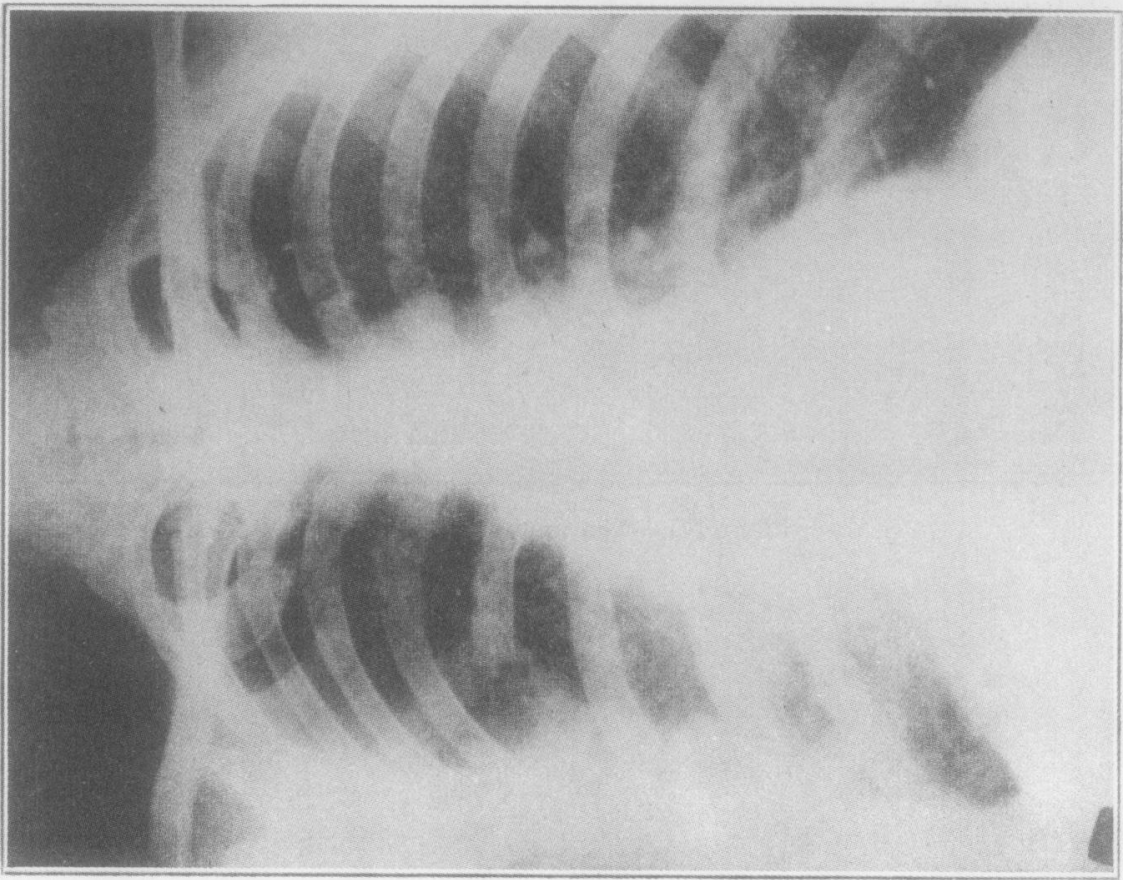

뭉

焉

峁 


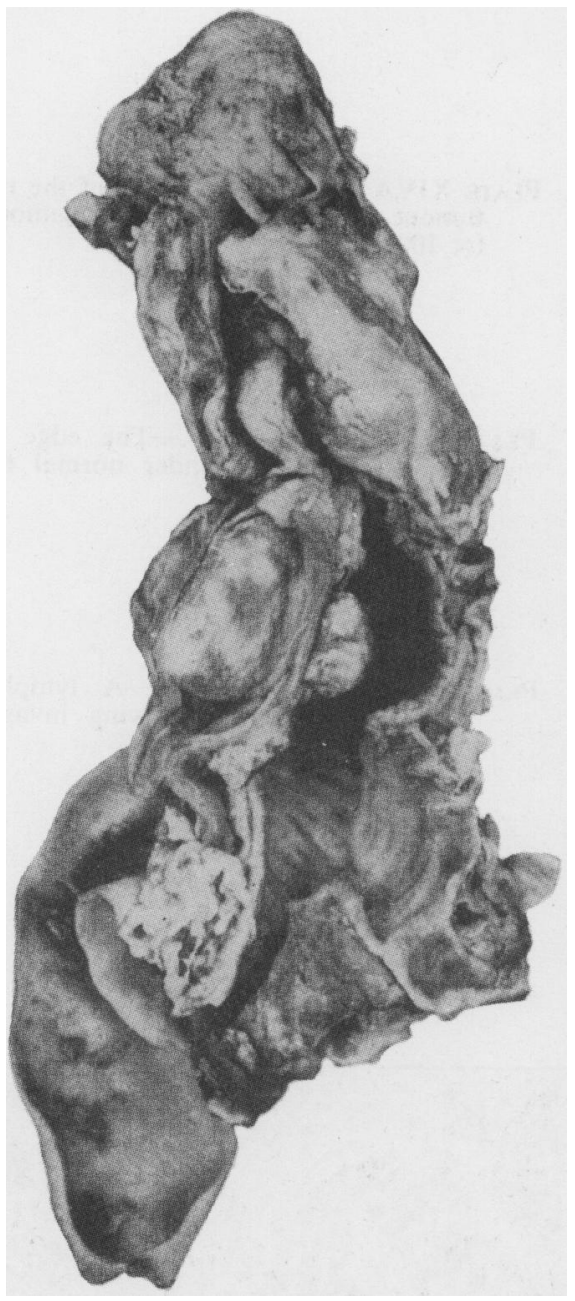

Plate XIIIA and B.-Macroscopic appearances of the tracheal tumour.

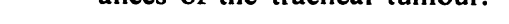

Plate XIIIA

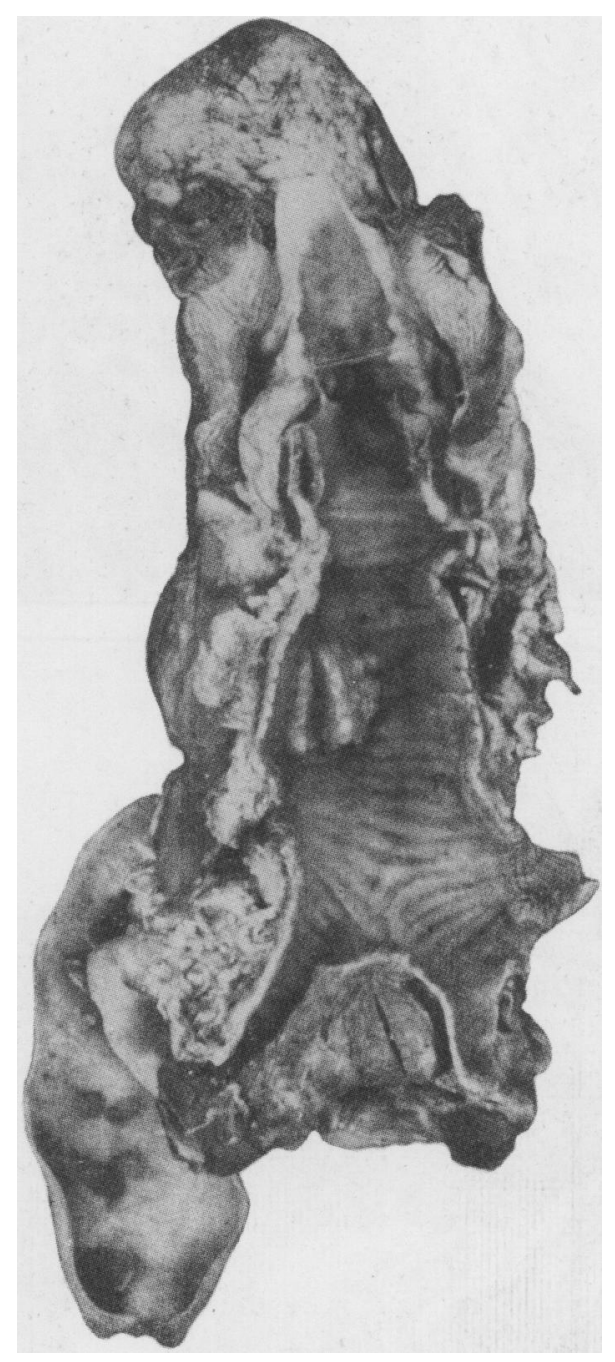

Plate Xilib 


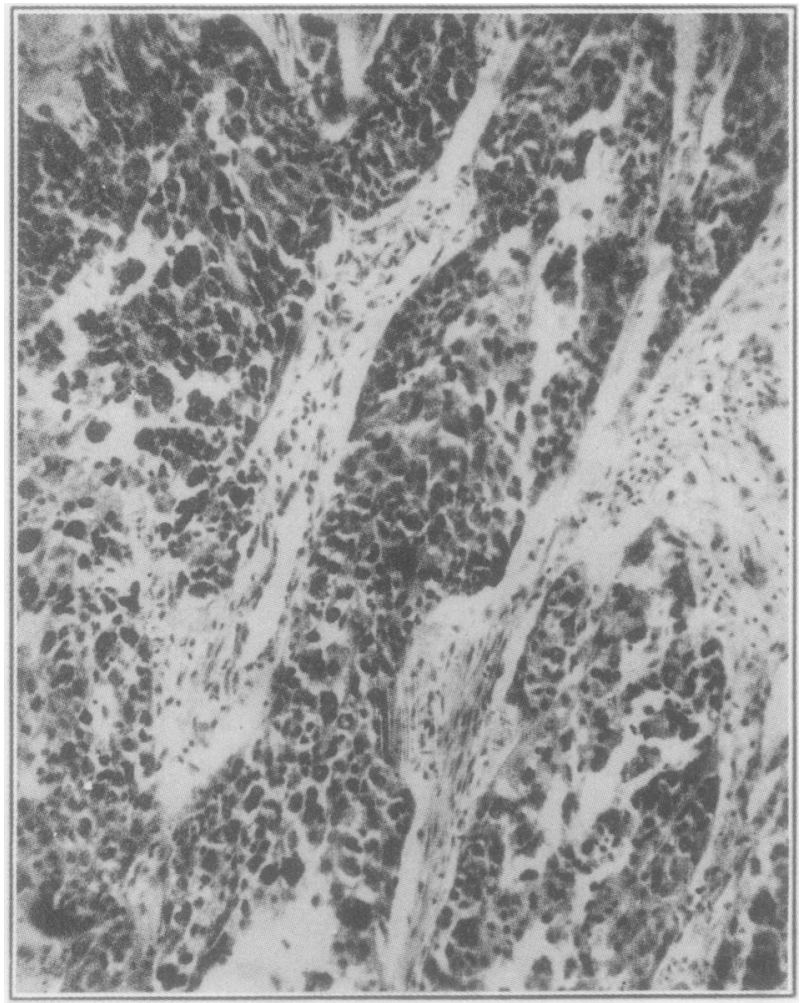

Plate XIVA (top left).-Section of the tracheal tumour, showing masses of squamous cells ( $\times 100)$.

Plate XIVC (lower right).-A lymph node behind the trachea showing invasion by growth ( $\times 75)$.

Plate XIVB (lower left).-The edge of the tumour infiltrating under normal tracheal epithelium $(\times 75)$.
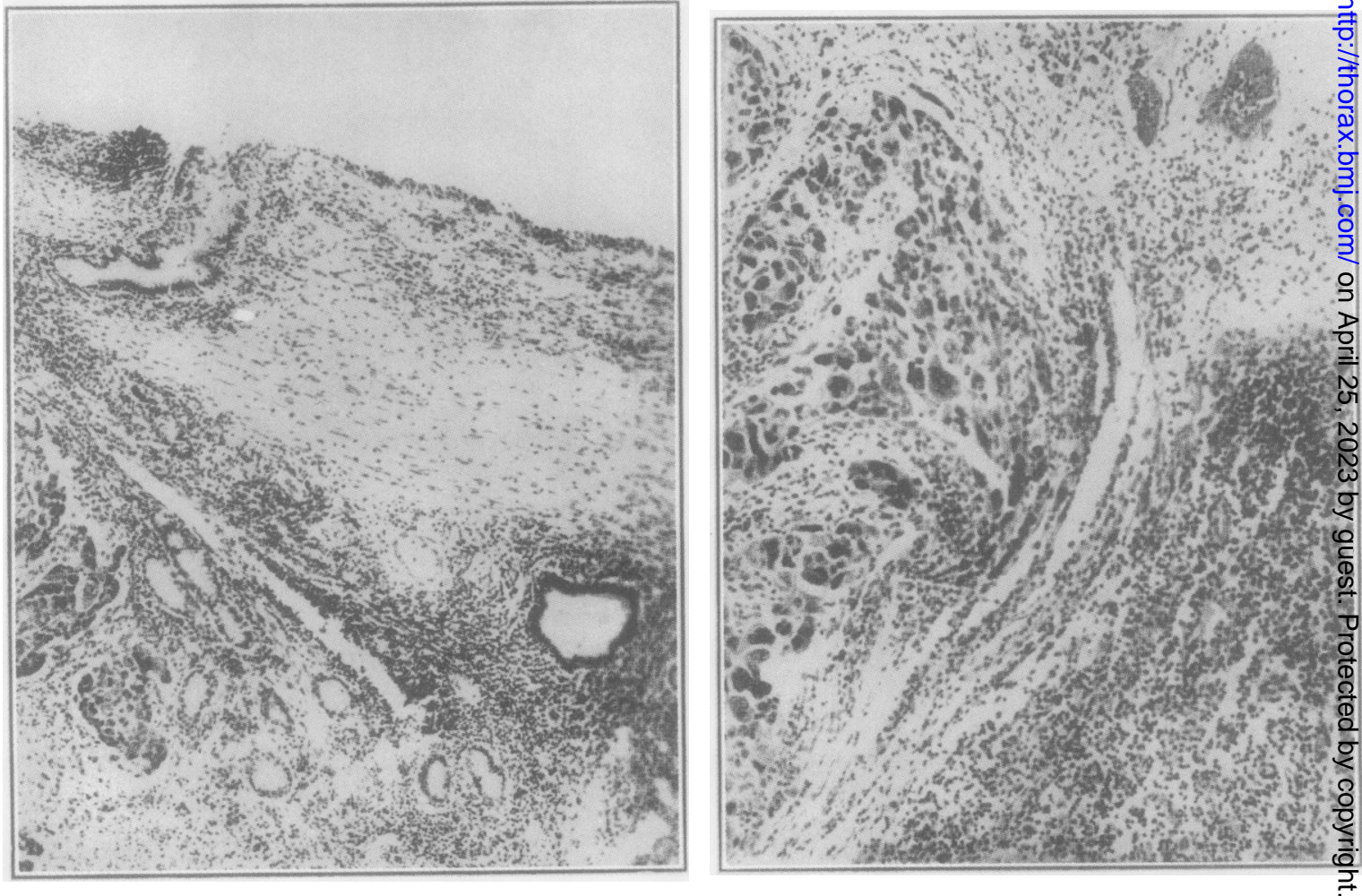